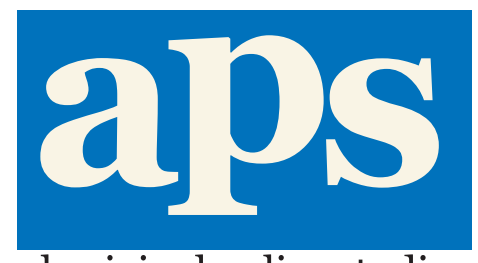

aboriginal policy studies

\title{
Article
}

\section{Aboriginal Languages in Urban Canada: A Decade in Review, 1996 to 2006}

\author{
Mary Jane Norris
}

aboriginal policy studies, Vol. 1, no. 2, 2011, pp. 4-67

This article can be found at:

http://ejournals.library.ualberta.ca/index.php/aps/article/view/8965

ISSN: 1923-3299

Article DOI: $10.5663 / a p s . v 1 i 2.8965$

aboriginal policy studies is an online, peer-reviewed and multidisciplinary journal that publishes original, scholarly, and policy-relevant research on issues relevant to Métis, non-status Indians and urban Aboriginal people in Canada. For more information, please contact us at apsjournal@ualberta.ca or visit our website at

www.ualberta.ca/NATIVESTUDIES/aps/

or

http://ejournals.library.ualberta.ca/index.php/aps/ 


\title{
Aboriginal Languages in Urban Canada: A Decade in Review, 1996 to $2006^{1,2}$
}

\author{
Mary Jane Norris \\ Consultant
}

\begin{abstract}
Canada's Indigenous languages and cultures are generally associated with Aboriginal communities and reserves outside of cities. Yet in both the 1996 and the 2006 Censuses, close to one in five persons who reported an Aboriginal mother tongue lived within the boundaries of a major Canadian city. This article explores the situation of Aboriginal languages within Canada's urban areas in general. It presents for the first time a demographic analysis of urban trends and changes in Aboriginal languages over the decade between 1996 and 2006. Results yield useful insights into how Aboriginal languages have been faring within Canadian cities, with respect to size and viability; language use, transmission and learning; and first and second language speakers. The implications of these findings for language prospects of Aboriginal peoples in Canada's cities suggest continued challenges, needs and requirements for support in maintaining their traditional languages within an urban environment.
\end{abstract}

\section{Introduction}

Canada's Indigenous languages and cultures are generally associated with Aboriginal communities and reserves outside of cities. Yet, both the 1996 and 2006 Censuses show that close to one in five persons who reported an Aboriginal mother tongue over the past decade resided within the boundaries of a major Canadian city, numbering about forty-two thousand persons in 2006. This study explores the situation of Aboriginal languages within Canada's cities, and how it contrasts with that of Aboriginal communities and reserves. And, for the first time, building on a previous 1996 Censusbased study (Norris and Jantzen 2003), this article provides an analysis of urban trends and changes in Aboriginal languages over the decade from 
1996 to 2006. Results provide useful insights into how Aboriginal languages in urban Canada have been faring over the decade. Demographic measures and indicators of languages in urban areas address speaker numbers and residential distributions, patterns of home language use, transmission and first- and second- language learning and speaker composition. The implications of these findings consider the language prospects of Aboriginal people in cities, suggesting continuing challenges and requirements for supporting the maintenance and revitalization of their traditional languages, and cultural connections.

\section{Outline of Discussion}

The article begins with three sections: the significance of Aboriginal languages in general in relation to culture, identity, and well-being; the urban situation of Aboriginal languages in relation to challenges, opportunities, and well-being; and, census-related research focusing on urban-specific demographics and indicators of Aboriginal languages. Some background is provided on the census data, approach, and methodology used in this study, and on the diversity and state of Aboriginal languages in Canada. Summary data and indicators from the 1996 and 2006 Censuses are presented for individual Aboriginal languages, along with selected language and residential characteristics of First Nations, Inuit, and Métis speakers. A demographic analysis over the 1996 to 2006 Census decade explores the state, patterns and trends of Aboriginal languages within urban areas. The paper concludes with the implications of these findings for Aboriginal language prospects within urban Canada.

\section{Aboriginal Languages: Significance for Aboriginal Culture, Identity, and Well-being}

As the Royal Commission on Aboriginal People (RCAP) indicated in 1996, language is "the principal instrument by which culture is transmitted from one generation to another, by which members of a culture communicate meaning and make sense of their shared experience." (RCAP 1996a, 602) Language is an important means of transmitting culture, traditions, and beliefs to new generations, and is a way of expressing networks of social relationships (Crystal, 2000). A language represents a unique world view, reflecting the knowledge, culture, and identity of a people and, as Ken Hale 
said, "Language embodies the intellectual wealth of the people who speak them" (qtd. in Abley 2003, 126). Language is significant as it relates to Aboriginal culture and a sense of Aboriginal identity in Canada, as it "is not only a means of communication but a link that connects people with their past and grounds their social, emotional, and spiritual vitality - its importance to Indigenous people is immense . . . Although loss of language doesn't necessarily lead to the death of a culture, it can severely handicap transmission of that culture" (Norris 1998, 8).

Many Aboriginal communities have experienced the devastating impacts of cultural alienation and language loss, of children being raised without their culture, language, and traditions, losing connection with their past, history, traditional knowledge, and the land. . . . both individual and collective identity can be weakened and cultural loss can occur . . . in many aspects of daily life, in traditional ceremonies, and in spiritual teachings (Norris 2011, 115).

Strong cultural attachment and a strong sense of identity are important components of well-being. The Royal Commission on Aboriginal Peoples indicated that the maintenance of the Aboriginal language and group integrity has both a socio-emotional and a spiritual purpose (RCAP, 1996a, 613); and considered the revitalization of Aboriginal languages in Canada to be an important component for building both healthy individuals and healthy communities (Bougie 2010). Language maintenance and revitalization have been linked with health, well-being, positive educational outcomes, and improved life chances. A number of studies suggest the process of learning an Aboriginal language may contribute to cultural continuity, increased selfesteem among youth, and to community healing and well-being (Ball 2009; Chandler 2006; Chandler and Lalonde 2008; Task Force on Aboriginal Languages and Cultures 2005; from Norris 2011, 116).

\section{Aboriginal Languages in Schools: Children's Self-esteem and Educational Outcomes}

An important dimension of well-being is connected to education. The literature shows evidence that indicates that exposure to Aboriginal cultures and language within schools can be associated with increased self-esteem and positive learning outcomes among Aboriginal children. For example, 
Guèvremont and Kohen (2011) cite studies of Inuit language immersion programs in Nunavik which demonstrated positive impacts on children's selfesteem and academic outcomes, and the importance of a strong foundation in an Aboriginal language education program (Louis and Taylor 2001; Wright and Taylor 1995). Furthermore, change in the language instruction of children from solely an Aboriginal language to solely in English or French was associated with a decrease in their self-esteem (Bougie, Wright and Taylor, 2003).

Guèvremont and Kohen explore the association between knowledge of an Aboriginal language and school outcomes for children and adults, by residence on selected reserves and off-reserve, based on an analysis of 2001 Aboriginal Peoples Survey data. Their study, which reveals the significance of teaching traditional First Nation and Inuit languages in schools, may be the first study using population data to report positive associations of speaking an Aboriginal language with school outcomes.. Their findings suggest "...positive and possibly protective effects of being taught an Aboriginal language on school outcomes and the importance of the supportive environment where teachers help children learn an Aboriginal language in the school setting." (Guèvremont and Kohen, 17). For example, among First Nation children, both on and off-reserve, those who spoke a First Nation language and who were not helped to learn the language by their schoolteachers were less likely to look forward to going to school as compared to who did not speak an Aboriginal language. However, a similar positive association between language and school outcomes was not evident among adults, in that those who spoke an Aboriginal language were less likely than those who did not speak an Aboriginal language to have completed high school, whether they had been taught the language or not. However, this was not the case for post-secondary outcomes: “...for adults who had completed high school, those who spoke an Aboriginal language were no less likely to have completed post-secondary levels of schooling than adults who did not speak an Aboriginal language" (Guèvremont and Kohen, 15).

\section{Aboriginal Youth Maintaining and Learning Their Traditional Languages}

Trends suggesting renewed interest in the vitality of Aboriginal languages, especially among Aboriginal youth, and signs of revitalization are good 
news not only for the survival of endangered languages but also for bridging the connections across generations (Norris 2007, 2008, 2009; Tulloch 2005,2008$)$. The ability to speak the language of their ancestors affords youth opportunities to communicate with older family members in their traditional language, which can contribute to the maintenance of traditional cultures across generations. A study based on 2006 APS data, which explored the participation of children and youth in sports and cultural activities by Inuit, Métis, and off-reserve First Nations, showed that children using an Aboriginal language or spending time with elders were more likely to participate in cultural activities (Smith, Findlay and Crompton 2010, 55). Research on suicide among Aboriginal youth suggests that efforts to maintain and revitalize traditional culture and language can have significant implications for the well-being of Aboriginal youth and their communities:

[I]ndividual and cultural continuity are strongly linked, such that First Nations communities that succeed in taking steps to preserve their heritage culture and work to control their own destinies are dramatically more successful in insulating their youth against the risks of suicide (Chandler 2008, 72).

\section{Aboriginal Languages in Urban Areas: Challenges, Opportunities, and Well-being}

Findings from the 1996 Royal Commission demonstrated that many of the challenges confronting Aboriginal languages are exacerbated in an urban environment. While it was noted that urbanization can include frequent moves to and from home communities that can help maintain connections with culture, it was also recognized that not all Aboriginal people in urban areas have links with a home community, and that for many the city has become a permanent home (RCAP 1996b, 523-37).

More recently, in a discussion of research into urban Aboriginal identities in Canada, Peters $(2011,85)$ considered the impact of city populations and characteristics, Aboriginal and non-Aboriginal, in creating challenges for "the emergence and maintenance of positive urban Aboriginal identities." Measures and indicators of urban Aboriginal languages presented here in this article also reflect the impact of some of these challenges Peters identified, especially in relation to "being surrounded by non-Aboriginal people and cultures" and of "heterogeneity." As this study demonstrates, 
patterns of Aboriginal home language among urban Aboriginal residents attest to the impact of the larger mainstream languages. Also, the significant diversity and variations in the state of the many different Aboriginal languages spoken throughout Canada's Aboriginal communities and reserves are reflected across the country in urban areas as well (Norris and Jantzen, 2003); and reinforces the observation that "acknowledging the diversity of urban Aboriginal communities is an important basis for public policy" (91).

\section{Sources of Language Learning and Support for Children and Youth in Urban Areas}

In order to foster language learning, it has become increasingly important to consider the access youth have to sources of learning and the domains in which they may use their language, both within and outside Aboriginal communities. While Aboriginal Peoples Survey (APS) results reinforce the importance of parents and the home use of languages, the surveys also point to other important sources of learning for children, including their extended family of aunts, uncles, and grandparents; teachers in schools; other persons; and the community itself. The surveys also suggest the more sources children receive help in learning their Aboriginal language, the less difficulty they have in understanding the language (Norris 2004, 2008b). Even in the case of relatively strong languages like Inuktitut, Inuit youth who say that they do not want to lose their ability to speak Inuktitut well also identify a need for support through family, community, and education, along with opportunities to learn, hear and use the language (Tulloch 2005).

Within an urban environment, sources and support for youth learning their traditional language can be even more challenging, and learning situations can vary considerably from one city to another depending on language characteristics of their Aboriginal residents. This situation is illustrated by the sharp contrasts between the cities of Winnipeg and Toronto. According to 2001 APS data, Winnipeg has the largest population with an Aboriginal mother tongue and/or ability to speak an Aboriginal language amongst Canadian cities. Toronto is one of the smallest. In Winnipeg, practically half (49\%) of the Aboriginal adults surveyed indicate the ability to speak an Aboriginal language very well or relatively well, compared to just 19 percent of Toronto Aboriginal adults. These differences are reflected in their sources of language learning for children: in Winnipeg, parents 
and other family members are the major sources of learning an Aboriginal language for children, with teachers and other persons accounting for only

6 percent and 18 percent respectively. In Toronto, teachers (39\%) and other persons (62\%) are the major sources of learning (Norris 2008b).

Other city-based studies identify a variety of learning sources and supports that contribute to Aboriginal culture and identity within the urban community (Peters, 2011), many of which can also be applicable to languages. For example, twenty Winnipeg Aboriginal youth in a study of by Belanger et al. (2003) indicated that their grandparents were important sources of Aboriginal cultural identities, along with Aboriginal programming in the city and in the media (Peters 2011, 92-3).

\section{Importance of Home Language Use and Prospects in Urban Areas}

The viability or continuity of a language is dependent on it being used on a daily basis, ideally as the primary home language (RCAP 1996a). Demographic analyses of Aboriginal language data over previous and current censuses have consistently demonstrated the strong association between home language use and the health of a language, so that those languages spoken most often at home tend to have younger populations reporting an Aboriginal mother tongue (Norris 1998, 2003, 2007). However, many Aboriginal children and youth today do not live in the "ideal" conditions for acquiring an Aboriginal mother tongue through major home use - that is, they are not living in Aboriginal communities and families where both parents have an Aboriginal mother tongue (Norris 2003, 2007, 2008, 2009). Long-term trends of declining home language use have yielded diminishing proportions of children and consequent aging Aboriginal mother tongue populations (Norris 2007, 2008).

A study of young First Nations children living off-reserve in Canada, based on the 2006 Aboriginal Children's survey, also demonstrated and quantified the significance of home language use. In it, the odds of understanding an Aboriginal language for young off-reserve First Nations children who were exposed to an Aboriginal language on a daily basis at home were 6.6 times the odds for children who were not (Bougie 2010, 78)

As this article and previous research demonstrate (Norris and Jantzen 2003; Norris forthcoming), the challenges of speaking an Aboriginal language as a major home language are especially pronounced in urban areas, where the effects of "being surrounded by non-Aboriginal people 
and cultures" and contending with the prevailing influence of English and French in media, popular culture, and the market place have important implications for how youth learn their traditional languages.

\section{Research on Aboriginal Languages in Canada's Urban Areas: Indicators for Policy}

Census-based indicators on the state and change of Aboriginal language situations within urban areas, as well as in Aboriginal communities and reserves, can further the understanding of the main issues surrounding the maintenance and revitalization of languages and their implications for programs and policies. However, much of the previous demographic research on Aboriginal languages has focused largely on the state of Aboriginal languages overall and in Aboriginal communities, reserves, and settlements (e.g., Norris 1998, 2006, 2007). Outside of Aboriginal communities and reserves, most of the existing statistical research on Aboriginal languages, based on census and survey data (including the Aboriginal Peoples Survey 1991 and 2001, and the Aboriginal Children's Survey 2006) has tended to focus on the "off-reserve" population but not specifically on the urban population (e.g., Bougie 2010; Guevremont and Kohen 2011; Smith, Findlay, and Crompton 2010; Statistics Canada 2009, 2008).

Previous research on Aboriginal languages with a focus on urban areas and individual cities was undertaken based on the 1996 Census (Norris and Jantzen 2003), and forms the basis for the comparison with the 2006 Census in the analysis presented here. While there appears to be relatively little other previous demographic research on Aboriginal languages with an urban focus, more recent research on urban areas (Norris forthcoming) has been undertaken with the National Association of Friendship Centres (NAFC) as part of the Urban Aboriginal Knowledge Network (UAKN). This study explores the state, diversity, and prospects of Aboriginal languages among Aboriginal populations residing within the catchment areas of Friendship Centres, comprising 304 communities across Canada, including the catchment areas of 116 existing Friendship Centres (FCs) and 188 potential Friendship Centre or "gap" (non-reserve areas) deemed to have the potential to become FCs given their significant Aboriginal populations. Patterns and variations of language learning and use are explored across geography, by regions, and by catchment population size, ranging from small rural to large urban areas, and also by broad age groups and gender. The study comprises 
a number of key aspects concerning language outcomes and prospects, with a focus on language learning, maintenance, and revitalization, especially in relation to youth. There is a special emphasis on the role of second language learning and (at least) regular home use as increasingly important components of language survival, maintenance, and revitalization within Friendship Centre communities (Norris forthcoming).

\section{Relevance to the Urban Aboriginal Community}

This article, in exploring similarities and differences of urban language situations between 1996 and 2006, addresses the knowledge gap in urban language trends in city settings in general. Using relatively simple indicators, graphs, and tables, the findings provide some measures of the state and changes in the urban situations of Aboriginal languages. As such, within the context of policy and programs, these language indicators can serve to establish benchmarks and contribute to an assessment of Aboriginal languages trends within urban areas in general. In addition, as Christa Rust $(2010,56)$ noted, indicators can also "become tools for change and learning ... [and] . . . serve to raise awareness of concerns and issues."

Recent research suggests that some of the language indicators employed in this study may also have relevance within the urban Aboriginal community, from the perspective of Aboriginal well-being. Members of Winnipeg's urban First Nations community, engaged in a project concerning the identification of issues and indicators related to their community wellbeing, recognized cultural identity as a key issue within the cultural domain. In this process of community involvement, the measure of "The number of First Nations who can speak their native language" was highlighted as an important indicator of cultural identity (Rust 2010,55-65), and is similar to measures utilized in this study.

\section{Census Data on Aboriginal Languages: Concepts, Definitions, Limitations, and Coverage}

This paper uses the most recent 2006 Census data to build upon findings from a previous 1996 Census-based analysis (Norris and Jantzen 2003) in exploring the situation of Aboriginal languages in urban centres over the past decade. 


\section{Aboriginal Populations and Geography}

Census data on Aboriginal languages are analysed here specifically for the Aboriginal identity population (comprising those who identify as North American Indian, Métis, or Inuit, and/or who are Registered Indian and/ or band members). While most of the analysis is based on the Aboriginal identity population as a whole, especially for the 1996 and 2006 Census years, there is also an analysis of 2006 language data by four individual identity groups of Registered Indians, non-Registered Indians, Métis, and Inuit. Two different sets of geographic classifications, both utilizing onand off-reserve geography, are used in the analysis of Aboriginal language patterns place of residence. For comparison purposes, the analysis of patterns between the 1996 and 2006 Censuses is based on the geographic classification utilized in the 1996 Census-based study, which consisted of five categories distinguishing between locations within and outside cities. The second geographic classification consists of four categories that include distinctions between small and large cities, employed here with the 2006 Census data, for other types of analyses that were not undertaken with the previous 1996 Census study -in particular those concerning: language patterns of individual Aboriginal identity groups; distinctions between most frequent and regular home use of Aboriginal languages (a variable introduced after the 1996 Census in 2001); and more detailed crossclassifications of language patterns by age and place of residence. Details on population and geography are provided in the section Aboriginal Population and Geography: Census Concepts, Definitions and Classifications Used in this Study.

\section{Aboriginal Populations and Geography: Census Concepts,Definitions and Classifications Used in this Study}

The following discussion addresses current census concepts and definitions pertaining to the Aboriginal populations and geographic classifications used in this study.

\section{Aboriginal Populations}

Both the 1996 and 2006 Censuses allow the Aboriginal population to be defined according to a number of different concepts and criteria, including ethnic origin (ancestry), Aboriginal identity (self-reported affiliation with an Aboriginal group), Registered Indian (legal status), 
and First Nation Affiliation or band membership. Analyses in this paper for the 19962006 period are based on the total population that reported an Aboriginal identity (North American Indian, Métis, or Inuit), and/or reported registration under the Indian Act, and/or reported membership in an Indian band or First Nation. According to this definition, the total Aboriginal identity population numbered about 799,000 in the 1996 Census, and 1,172,790 in 2006. Aboriginal language characteristics based only on 2006 Census data were analysed for separate Aboriginal identity populations and were configured into four mutually exclusive and exhaustive groups: 623,780 Registered Indians (regardless of Aboriginal identity); non-Registered 133,160 Indians; 355,500 Métis (non-Registered); and 49,110 Inuit (nonRegistered).

\section{Geographic Classifications}

\section{Urban, Rural, and Reserve Geographies at the National Level}

Two different configurations of urban geography were used in this study at the national level on the basis of urban areas in census geography.

Different types of urban areas comprise census geography. The census defines an urban area as having:

a population of at least 1,000 and no fewer than 400 persons per square kilometre ... All territory outside urban areas is classified as rural. Taken together, urban and rural areas cover all of Canada. Urban population includes all population living in the urban cores, secondary urban cores and urban fringes of census metropolitan areas (CMAs) and census agglomerations (CAs), as well as the population living in urban areas outside CMAs and CAs (Statistics Canada 2010, 231).

A CMA is defined on the basis of urban areas with a minimum core population of 100,000 ; similarly, a minimum of 10,000 is required for a CA.

Reserves, as well as rural fringes, can lie within both CMAs and CAs. In this study, settlements are grouped with Indian reserves into one geographic area. Settlements include Crown land and other communities with Aboriginal populations as defined by Indian and Northern Affairs Canada. Settlements can also include some, but not all, of the Métis and Inuit communities. Aboriginal communities outside of reserves fall within the rural classification of residence, such that some of the Métis and non-Registered Indian populations, as well as Inuit, would be residing in Aboriginal communities. 
Two separate geographic classifications in this study were developed from different configurations of urban geography, both distinguishing between on and off-reserve areas.

The first geographic classification used in language analyses for both 1996 and 2006 is the same as one employed in the previous 1996 Census-based study on Aboriginal languages (Norris and Jantzen, 2003) for purposes of comparison. It incorporates distinctions between locations within and outside cities, and consists of five categories: (1) Reserves and settlements; (2) Off-reserve; (3) Cities-CMA/CAs (not including smaller urban areas) (includes reserves within CMA/CA boundaries); (4) Cities-CMA/CAs Adjusted (excludes reserves within CMA/CA boundaries); and (5) Areas Outside CMA/CAs (includes reserves within CMA/CA boundaries).

The second geographic classification is used in language analyses for only 2006, for other aspects not undertaken with the previous 1996 Census study. It incorporates a separate geographic category of "cities," comprising large cities based on CMAs, and smaller cities based on CAs and smaller urban areas. It consists of four mutually exclusive and exhaustive categories: (1) Indian reserves and settlements; (2) rural areas off-reserve; (3) urban CMAs (excluding reserves and rural fringes), and (4) urban non-CMA areas (that is, all other urban areas outside of urban CMAs, including urban areas of CAs and smaller urban areas). Rural areas comprise all remaining areas, including the undeveloped fringes of urban areas, but excluding Indian reserves and settlements.

\section{Aboriginal Language Variables and Indicators}

Census language variables, including mother tongue, home language, and knowledge of an Aboriginal language (ability to conduct a conversation), are employed to assess the state of Aboriginal languages in urban Canada, identifying patterns, trends, and changes over the ten-year period from 1996 to 2006. Analytical discussions address the extent to which Aboriginal languages are being learned, either transmitted as a mother tongue (first language) or as a second language, especially among children and youth, by place of residence.

This study includes a variety of language measures and indicators. Two indexes are applied in this analysis: one based on Aboriginal language data for home language and mother tongue, and the other based on language knowledge and mother tongue. The first is the calculation of the Continuity 
Index, which indicates the degree to which a language is being transmitted as a first language in the home. The second is the calculation for the Ability or Second Language Index, which indicates the degree to which a language is being transmitted as a second language. An additional analytical approach demonstrates the relevancy of the distinction between the uses of an Aboriginal language on a "most often" versus a "regular" basis, especially for speakers of Aboriginal languages in cities, and provides new insight into the patterns of Aboriginal language use within the homes of Aboriginal urban residents. Details on language variables and indicators are provided in the section Census Language Variables and Aboriginal Language Indicators Used in Study.

\section{Census Language Variables and Aboriginal Language Indicators Used in Study}

Census Language Variables (Reference: Statistics Canada Census Dictionary, 2010)

Mother tongue refers to the first language learned at home in childhood and still understood by the individual at the time of the census. (Note: In this and a previous study (Norris 2007, 26), the terms mother tongue populations and first language speakers are not strictly equivalent concepts although the two terms are used interchangeably.)

Home language refers to the language spoken most often or on a regular basis at home by the individual at the time of the census.

Home language spoken "most often" is defined as language spoken "most often" at home by the individual at the time of the census.

Home language spoken "on a regular basis" is defined as language spoken on "a regular" basis at home by the individual at the time of the census. (Note: In the case of home language "spoken on a regular basis," comparisons between 1996 and 2006 are not possible since the question on "regular" home use was not introduced until 2001).

Knowledge of non-official languages refers to languages, other than English or French, in which the respondent can conduct a conversation.

(Note: Although respondents were instructed to report only those languages in which they can carry on a conversation of some length on various topics, ability is based on the respondent's own assessment. Since varying degrees of fluency may be represented in the 
data, it is suggested that some caution be exercised in considering the implications of second language acquisition for transmission and continuity. See Norris 2007, 26).

Language data are based on single and multiple responses for mother tongue and, home language for both 1996 and 2006 Censuses.

\section{Aboriginal Language Measures and Indicators by Place of Residence*}

Index of Continuity measures language continuity or vitality by comparing the number of people who speak a language at home to the number who learned that language as their mother tongue. To some extent it serves as an indicator of language maintenance: the lower the score, the greater the decline or erosion in the strength of the language. A ratio less than 100 indicates some decline (i.e., for every 100 people with an Aboriginal mother tongue, there are fewer than 100 in the overall population who use it at home).

Index of Ability or Second Language Acquisition (KN/MT) compares the number of people who report being able to speak the language with the number who have that Aboriginal language as a mother tongue. To some extent this index may suggest some degree of language revival. If, for every 100 people with a specific Aboriginal mother tongue, more than 100 persons in the overall population are able to speak that language, then some learned it as a second language either in school or later in life. Throughout this article it will be mostly referred to as the Index of Second Language Acquisition.

Average Age of the Aboriginal population reporting: i) an Aboriginal mother tongue (first language) and ii) the ability to speak an Aboriginal language.

*Number of Aboriginal people reporting: i) an Aboriginal mother tongue; ii) the ability to speak an Aboriginal language; iii) use of an Aboriginal home language on a "most often" basis"; and, iv) use of an Aboriginal home language on a "regular" basis.

*Proportion of Aboriginal people reporting: i) an Aboriginal mother tongue; ii) the ability to speak an Aboriginal language; iii) use of an Aboriginal home language on a "most often" basis; and iv) use of an Aboriginal home language on a "regular"" basis. (*Note: also provided by age groups for place of residence). 


\section{Limitations of Approach and Methodology: Considerations and Implications}

This study provides a demographic approach in the analysis of Aboriginal languages in Canada's cities based on both 1996 and 2006 Census data. The methodology involves the application of two types of Aboriginal language indicators; one the index of continuity - concerning language viability and transmission; and the other, the index of second language acquisition - in relation to second language learning. For both the1996 and 2006 Censuses, these indicators reflect the ratios of Aboriginal home language users and persons able to speak an Aboriginal language in relation to the Aboriginal population reporting an Aboriginal mother tongue. As such, these measures relate only to the Aboriginal identity population in each census reporting an Aboriginal language mother tongue, home use, or knowledge - not the total identity population. A second set of measures over the decade include proportions of the Aboriginal identity population reporting an Aboriginal mother tongue, home language, or language knowledge, which, unlike the indexes, include the total population size of the Aboriginal identity population in their calculation.

With respect to limitations of the approach and methodology used in this study, there are a number of considerations associated with the comparison of the Aboriginal identity population from one census to the next, which concern intercensal variations in census coverage and geography; intercensal growth and compositional effects on Aboriginal populations; and construction of language measures. Details on these considerations and their implications are outlined in the section Limitations of Approach and Methodology: Considerations and Implications.

The most significant considerations with respect to the limitations of approach and methodology are associated with factors related to the growth and changing composition of the Aboriginal identity population between censuses, especially in their implications for the interpretation of findings. Two major considerations linked to growth and compositional effects include: first, the rapid growth of Aboriginal populations over the 1996 to 2006 Censuses, particularly associated with ethnic mobility, that is, changes in the reporting of Aboriginal identity from one census to the next; and, second, the impact of Aboriginal mobility and migration on Aboriginal languages, especially in relation to the impact of Registered Indian migration on language continuity in urban areas. The growth effect of 
ethnic mobility poses an issue for assessing the proportions of the Aboriginal identity population reporting an Aboriginal language (mother tongue, home language, or language knowledge) between 1996 and 2006. Declines in these proportions over the decade need to be interpreted with some caution, particularly for those Aboriginal populations such as the Métis, who saw significant population growth over the decade through the effects of ethnic mobility. The large increase in the Métis population between 1996 and 2006 is in itself a significant factor in the declining proportions of Métis reporting an Aboriginal mother tongue. The migration from reserves of Registered Indians, who are more likely to have an Aboriginal mother tongue, could have compositional effects on language continuity in urban areas and implications for the interpretation of language indexes of continuity and second language acquisition. For example, differences observed in the index of second language acquisition in urban areas between 1996 and 2006 may not simply be related to differences in the propensity to learn an Aboriginal language as a second language, but also to changes in the populations of first and second language speakers due to migration.

\section{Limitations of Approach and Methodology: Considerations and Implications}

Three sets of factors identified here in connection with the limitations of the approach and methodology used in this study concern: intercensal variations in census coverage and geography; intercensal growth and compositional effects on Aboriginal populations; and construction of language measures.

\section{A. Factors Affecting Comparability of 1996 and 2006 Censuses:}

Comparability between the 1996 and 2006 Censuses is limited to some extent given that data in this study have not been adjusted for intercensal differences in under coverage of the Aboriginal population, including incomplete enumeration of reserves, which can result in under /over estimates of residential distributions of Aboriginal populations by on and offreserve, in rural and urban areas (Norris and Clatworthy 2011). Data have not been adjusted for intercensal differences in geography, such as the addition or deletion of CMA/CAs, changing boundaries, and classifications, which to some degree can affect the urbanization of Aboriginal people (Norris and Clatworthy 2011). Despite their limitations, unadjusted census data nevertheless can still provide a fairly reliable picture of the Aboriginal language situation of in urban areas over the past decade. 


\section{B. Factors Affecting Growth and Changing Composition of Aboriginal Identity Population Between 1996 and 2006.}

Factors related to the growth and changing composition of the Aboriginal identity between censuses can affect the comparability of various cultural, socio-economic, and demographic characteristics, including language. A significant factor affecting the rapid growth of Aboriginal populations enumerated over the 1996-2001 and 2001-2006 periods, especially among Métis and in urban areas, has been attributed to phenomenon of ethnic mobility; that is, changes in self-reporting of Aboriginal identity from one census to the next (Guimond, Robitaille, and Senécal 2009, 11-17). Apart from ethnic mobility, demographic factors related to natural increase (births minus deaths) and high fertility, and to mobility and migration, are also important considerations that can both directly and indirectly affect the growth and composition of the Aboriginal population in urban areas over censuses (Norris and Clatworthy 2011). Their impacts are reflected in the outcomes of: a growing and young Aboriginal population and the contribution of net inflows of younger cohorts of migrants to urban areas (Clatworthy 2009, 50), differences across individual Aboriginal groups, in their levels and patterns of migration to and from cities (Clatworthy and Norris forthcoming), and in their differences in language characteristics (Norris 1998, 2000). All of these factors and their related effects as they impact on both the growth and composition of Aboriginal populations can have important implications for the interpretations of findings on patterns and trends in Aboriginal languages between 1996 and 2006. The following discussion assesses the implications in relation to the two important factors of ethnic mobility and geographic mobility / migration.

\section{Implications of Ethnic Mobility for the Analysis of Census Data on Aboriginal Languages}

While the impact of ethnic mobility does pose limitations in the comparison of Aboriginal identity populations and their characteristics over 1996 and 2006, it would appear that the impact is less pronounced in relation to populations reporting an Aboriginal mother tongue. Responses regarding an Aboriginal language as a mother tongue appear to be less vulnerable over censuses to changes in reporting on the part of respondents as compared to questions concerning Aboriginal identity. The concept of a mother tongue tends to be more objective (i.e., the language first learned in the home and still understood) and less subjective than that of identity. Previous analyses of census data on Aboriginal language data have consistently shown that counts of the Aboriginal mother tongue population are practically the same whether based on the identity population alone or on the total Canadian population (Norris 1998; 2000). To illustrate, in the 2006 Census (as in 1996), practically all $(99 \%)$ of the respondents who reported an Aboriginal mother tongue also reported an 
Aboriginal identity. Consequently, counts are relatively similar between the total Canadian population $(222,210)$ and those based on the Aboriginal identity population alone $(219,155)$. The analysis of Aboriginal languages, whether based on the "Aboriginal Identity" population alone or the total population, regardless of identity, does not significantly alter the relative size of the study population of individuals reporting an Aboriginal mother tongue between the two censuses.

\section{Size of Aboriginal Mother Tongue Population}

Thus, in spite of the significant impact of ethnic mobility on the growth and size of the Aboriginal identity population overall, it would appear that the size of the Aboriginal mother tongue population is relatively unaffected by changes in reporting of Aboriginal identity. From another perspective, census data consistently show that persons who report an Aboriginal language as a mother tongue also tend to report an Aboriginal identity. This same conclusion also holds in urban areas, the focus of this study, where ethnic mobility is even more of a consideration: of the 41,800 individuals in urban areas who reported an Aboriginal mother tongue in 2006, practically all (96\%), reported an Aboriginal identity. Thus, as the unit of analysis in this study, the "Aboriginal Identity" population does not appear to pose problems for comparing the Aboriginal mother tongue population from one census to the next, since size of the mother tongue population remains relatively the same whether selected on the basis of Aboriginal identity or for the total Canadian population.

\section{Indexes of Language Continuity and Second-Language Acquisition}

Similarly, it can be argued that the indexes of continuity and second language acquisition, measures calculated from Aboriginal language counts (mother tongue, home use, or knowledge), would also be less vulnerable to the effects of ethnic mobility than "identitybased" concepts of population. However, in this context, the census question on language knowledge is somewhat more subjective in nature than the mother tongue and home language

questions in asking respondents to determine whether they themselves have the "ability to speak the language well enough to conduct a conversation."

\section{Proportion of Aboriginal population Reporting an Aboriginal Mother Tongue}

While ethnic mobility does not appear to be a significant factor in the size of the Aboriginal mother tongue population, its effect on growth of the total identity population does pose an issue for the comparison of proportions of the Aboriginal identity population reporting an Aboriginal language (mother tongue, home language, or language knowledge). Trends 
over censuses in proportions need to be interpreted with some caution, particularly for those Aboriginal populations such as the Métis, which saw significant population growth over the decade through the effects of ethnic mobility. The large increase in the Métis population over the 1996-2006 decade is in itself a significant factor in the declining proportions of Métis reporting an Aboriginal mother tongue (Norris 2007, 27; Statistics Canada 2003).

\section{Effects of Mobility / Migration on Language and Implications for Findings}

Findings from the 1996,2001 and 2006 Censuses consistently show that Aboriginal populations in urban areas experience high levels of mobility, in the "churn" to and from cities and in high rates of residential mobility, at rates notably higher than the non-Aboriginal population (Clatworthy and Norris 2007, forthcoming). Within urban areas over the 2001-2006 Census period in particular, Registered Indians experienced higher five-year rates of migration than other Aboriginal groups (apart from Inuit in large urban areas) (Clatworthy 2009, 47). Unlike other Aboriginal groups, their patterns of migration include flows of migration to and from reserves, a contributing factor to their higher rates of migration in urban areas (Clatworthy and Norris forthcoming). In terms of language characteristics, much higher proportions of Registered Indians, especially those living on-reserve, report an Aboriginal mother tongue, compared to other Aboriginal identity groups of non-Registered Indians and Métis (Norris 1998, 2000; Clatworthy and Norris forthcoming). Language can also be a factor in Aboriginal mobility: according to an analysis of 1991 APS data on Aboriginal mobility and reasons for moves, the propensity to move can be affected by various personal attributes, including language and attachment to traditional culture as indicated by retention of an Aboriginal language (Clatworthy and Cooke 2000).

Consequently, the mobility and migration patterns of Registered Indians can have significant compositional effects on the Aboriginal mother tongue populations by residence, on reserves and off, and especially in large urban areas, a major destination of migrants from reserves. These effects pose implications for the assessment of indicators of language continuity and acquisition. For example, in a study of Friendship Centre Areas, "gender differences observed in the propensity to learn an Aboriginal language as a second language may be less related to gender differences in language learning but more to compositional

difference owing to other factors such as migration ... Gender differences in out-migration, residency and life expectancy can contribute to a higher proportion of women with an Aboriginal mother tongue, and hence lower the index of second language acquisition for females (since a higher proportion of female residents in urban areas have an Aboriginal mother tongue compared to males)" (Norris forthcoming). 


\section{Construction of Indexes of Language Continuity and Second Language Acquisition}

Both the index of continuity and the index of second language acquisition are indirect estimates based on ratios of independent populations. "As indirect estimates of second language acquisition, the index of second language acquisition, and the estimated intercensal growth in the numbers of second language speakers assume that all persons with an Aboriginal mother tongue also reported the ability to speak an Aboriginal language. As such they serve only as indicators, not as precise measures" (Norris 2007,26). This situation is also similar with the estimate of continuity, which assumes that all persons who reported speaking an Aboriginal language at home on a "most often" basis also reported an Aboriginal mother tongue.

\section{Background: Diversity and State of Aboriginal Languages in Canada}

The UNESCO Atlas of the World's Languages in Danger estimates that about ninety different individual languages are currently spoken in Canada by First Nations, Inuit, and Métis (Moseley 2010; Norris 2010; UNESCO 2009). Census data from Statistics Canada are based on a classification system of fifty individual Aboriginal languages or isolates (languages not related to any of the major families) that belong to eleven Aboriginal language families - ten First Nations, including Michif, which is spoken by Métis, and Inuit. The range in population size is considerable. According to the 2006 census, the three largest language families-Algonquian $(153,400)$, Inuktitut $(33,000)$, and Athapaskan $(20,400)$-represented 93 percent of persons with an Aboriginal mother tongue-the other eight language families and isolates account for the remaining 7 percent, of which the five smallest families account for only 1 percent (see Table 1). Many of the smaller endangered languages located in British Columbia (Salish, Tsimshian, Wakashan, Haida, Tlingit, and Kutenai) were never as widely dispersed, owing to geography, as were the more widespread and larger Algonquian family, which extended from the Atlantic to the Rockies (Norris 1998, 10).

The state and prospects of Canada's Aboriginal languages vary considerably. While some are flourishing and viable, many are endangered or nearing extinction. Aboriginal languages have already suffered great losses due to forces of modernization, discouragement in residential schools, the influence of dominant languages, and possibly because many Aboriginal languages have been predominantly oral. At the time of European contact, 
Table 1: Selected Indicators* for Aboriginal Language Vitality, Total Population, Canada, 2006

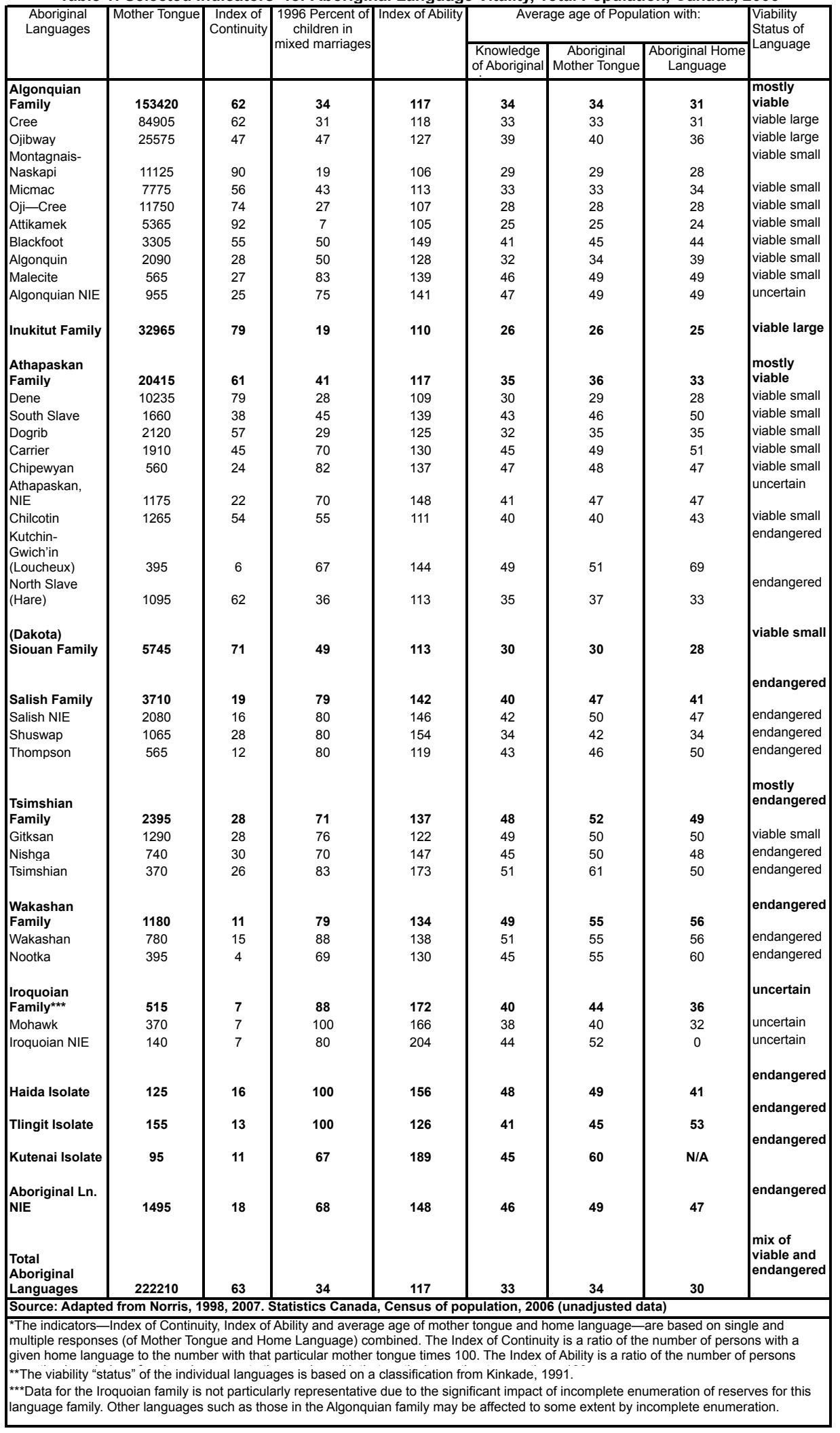


many more languages were spoken in Canada (Norris 1998). One estimate of survival suggests that "about a third of Aboriginal languages originally spoken in Canada have a good chance of survival. Fewer than half of the remaining languages are likely to survive for another fifty years" (Kinkade 1991).

\section{Data on Aboriginal Languages in Canada from the 1996 and 2006 Censuses}

Data from both the 1996 and 2006 Censuses show that a minority of the Aboriginal population in Canada report an Aboriginal language as a mother tongue or first language. Of the 1,172,800 people who identified as Aboriginal in the 2006 Census, 219,200 (19\%), reported an Aboriginal language as their mother tongue (or first language learned and still understood), as compared to $207,000(26 \%)$ of the identity population in 1996 . Even smaller shares report speaking an Aboriginal language at home: in 2006, about 138,000 $(12 \%)$ said it was the language they used most often at home, while another 5 percent reported it as a language they used on a regular basis at home. In the case of home language use, intercensal comparisons between 1996 and 2006 are not straightforward nor directly comparable, since the question concerning "regular" home use was not introduced until 2001. However, in the case of the 1996 Census, about 18 percent of Aboriginal people reported an Aboriginal language as that being spoken most often in the home. The fact that the proportions of Aboriginal people speaking their traditional language as their major home language are lower than their proportion with a mother tongue implies that learning an Aboriginal mother tongue does not guarantee continued use, and in some ways is consistent with the long-term decline in speaking Aboriginal languages at home.

On the other hand, both censuses indicate that there are more people who have knowledge of, or the ability to speak an Aboriginal language than people with an Aboriginal mother tongue, pointing to second language learners. In 2006, as in previous censuses, more Aboriginal respondents, some 252,000 (22\%) (compared to 234,000 , or $29 \%$, in 1996), reported that they could speak and understand an Aboriginal language well enough to conduct a conversation than those reporting an Aboriginal mother tongue (see Table 2 and Figure 1). Clearly, then, while some people shift from an Aboriginal language to another home language, others may be either learning Indigenous languages or beginning to use the language later in life. 
Table 2a: Aboriginal Identity Population by Language Counts, by On/Off-Reserve and City (CMA\&CA) Place of Residence, Canada, 1996 and 2006 Census

\begin{tabular}{|c|c|c|c|c|c|c|c|c|c|c|c|c|}
\hline & \multirow[t]{2}{*}{$\begin{array}{l}\text { Canada- } \\
\text { Total } \\
\text { residence } \\
\text { (1) }\end{array}$} & \multicolumn{2}{|c|}{$\begin{array}{c}\text { On-Reserve } \\
\text { (2) }\end{array}$} & \multicolumn{2}{|c|}{$\begin{array}{c}\text { Off-Reserve } \\
\text { (3) }\end{array}$} & \multicolumn{2}{|c|}{$\begin{array}{c}\text { Cities - CMA/CAs } \\
\text { (not including } \\
\text { smaller urban areas) } \\
\text { (includes reserves } \\
\text { within CMA/CA } \\
\text { boundaries) } \\
\text { (4) }\end{array}$} & \multicolumn{2}{|c|}{$\begin{array}{c}\text { Cities - CMA/CAs } \\
\text { Adjusted (not } \\
\text { including smaller } \\
\text { urban areas) } \\
\text { (excludes reserves } \\
\text { within CMA/CA } \\
\text { boundaries) } \\
\text { (5) }\end{array}$} & \multicolumn{3}{|c|}{$\begin{array}{c}\text { Population } \\
\text { Outside } \\
\text { CMA/CAs } \\
\text { (includes reserves } \\
\text { within CMA/CA } \\
\text { boundaries) } \\
(6)=(1)-(5)\end{array}$} \\
\hline & & \begin{tabular}{|c|} 
Total \\
number \\
of people
\end{tabular} & $\begin{array}{c}\% \text { of } \\
\text { Canada } \\
\text { total } \\
(2) /(1)\end{array}$ & \begin{tabular}{|c|} 
Total \\
number \\
of people
\end{tabular} & $\begin{array}{c}\% \text { of } \\
\text { Canada } \\
\text { total } \\
(3) /(1)\end{array}$ & $\begin{array}{c}\text { Total } \\
\text { number of } \\
\text { people }\end{array}$ & $\begin{array}{c}\% \text { of } \\
\text { Canada } \\
\text { total } \\
(4) /(1)\end{array}$ & $\begin{array}{c}\text { Total } \\
\text { number of } \\
\text { people }\end{array}$ & $\begin{array}{c}\% \text { of } \\
\text { Canada } \\
\text { total } \\
(5) /(1)\end{array}$ & $\begin{array}{c}\text { Total } \\
\text { number } \\
\text { of } \\
\text { people }\end{array}$ & & $\begin{array}{l}\% \text { of } \\
\text { anada } \\
\text { otal } \\
\text { ot(1) }\end{array}$ \\
\hline \multicolumn{13}{|c|}{1996 Census } \\
\hline Total Aboriginal* & 799,000 & 232,14 & $29 \%$ & 566,865 & $71 \%$ & 381,645 & $48 \%$ & 360,600 & $45 \%$ & 438,4 & & $55 \%$ \\
\hline Mother Tongue & 207,045 & 118,10 & $57 \%$ & 88,940 & $43 \%$ & 39,600 & $19 \%$ & 31,600 & $15 \%$ & 175,4 & & $85 \%$ \\
\hline Home Language & 145,390 & 94,12 & $65 \%$ & 51,270 & $35 \%$ & 15,200 & $10 \%$ & 9,500 & $7 \%$ & 135,8 & & $93 \%$ \\
\hline Knowledge & 233,900 & 128,13 & $55 \%$ & 105,765 & $45 \%$ & 52,500 & $22 \%$ & 43,400 & $19 \%$ & 190,5 & & $81 \%$ \\
\hline \multicolumn{13}{|c|}{2006 Census } \\
\hline Total Aboriginal* & $1,172,790$ & 308,49 & $26 \%$ & 864,295 & $74 \%$ & 621,000 & $53 \%$ & 576,400 & $49 \%$ & 596,3 & & $51 \%$ \\
\hline Mother Tongue & 219,155 & 138,38 & $63 \%$ & 80,765 & $37 \%$ & 42,060 & $19 \%$ & 27,895 & $13 \%$ & 191,2 & & $87 \%$ \\
\hline Home Language & 138,220 & 95,67 & $69 \%$ & 42,550 & $31 \%$ & 15,690 & $11 \%$ & 6805 & $5 \%$ & 131, & & $95 \%$ \\
\hline Knowledge & 252,045 & 154,40 & $61 \%$ & 97,640 & $39 \%$ & 53,340 & $21 \%$ & 37,145 & $15 \%$ & $214, \mathrm{c}$ & & $85 \%$ \\
\hline
\end{tabular}

Source: 1996 and 2006 Census of Canada (unadjusted data)

Table 2b. Aboriginal Identity Population by Language Counts, by On-Reserve, and Off-Reserve Rural, Urban nonCMA, and Urban CMA Place of Residence, Canada, 2006 Census

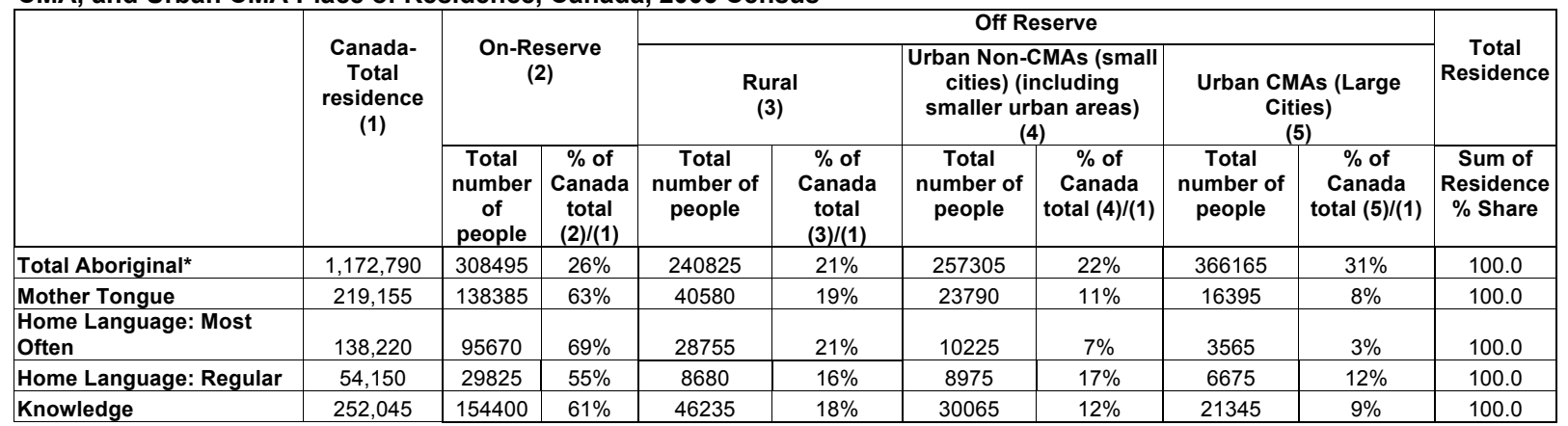

Source: 2006 Census of Canada (unadjusted data)

This is a phenomenon that appears to be especially pronounced in urban areas, and is also occurring for endangered languages, such that although younger generations may not be learning their Indigenous language as a mother tongue, there nevertheless appears to be strong interest in learning it as a second language (Norris 1998; Norris and Jantzen 2003; Norris 2007, 2008).

While the 2006 population counts of Aboriginal people with an Aboriginal mother tongue and ability to speak an Aboriginal language are higher overall than those of 1996, the corresponding 2006 proportions reporting an Aboriginal mother tongue or language knowledge are lower. Again, these declines over the decade need to be interpreted with some caution due to the effects of ethnic mobility on population growth. 
Figure 1: Percentage of Registered Indian Population reporting an Aboriginal Mother Tongue, by Residence On and Off Reserve, Canada, 1996, 2006

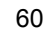

60

50

52

40

30

20

10

0

Total Residence

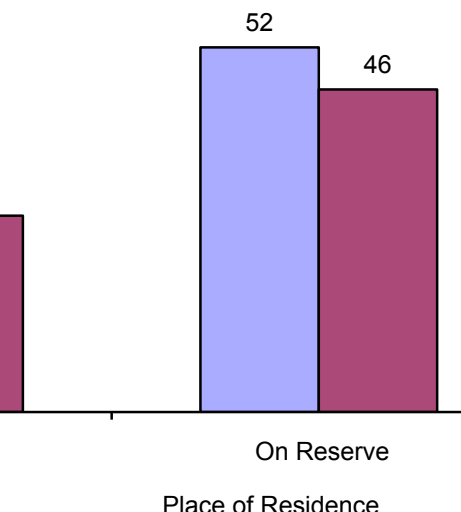

$\square 1996$

$\square 2006$

Source: 1996 and 2006 Census of Canada (unadjusted data)

First Nations, Métis, and Inuit: Speakers and Places

In the 2006 Census, and in the previous 1996 and 2001 Censuses, practically all $(99 \%)$ of the respondents who reported an Aboriginal mother tongue or home language, or knowledge of an Aboriginal language (98\%), also reported an Aboriginal identity (North American Indian [First Nations], Métis and Inuit) and/or Registered Indian status. However, First Nations, Métis, and Inuit differ significantly in their language characteristics, although language situations for all Aboriginal populations vary considerably by where they lived, whether in Aboriginal communities, reserves, settlements, rural or urban areas, cities large or small.

Place of residence is an important consideration in assessing the state of languages across Aboriginal groups, given that First Nations, Métis, and Inuit differ significantly in their degree of urbanization. In 2006, as in previous censuses, the most urbanized Aboriginal populations are nonRegistered Indians, with 74 percent living in urban areas, and Métis at 69 percent. Nearly one half of Registered Indians lived on-reserve, while 40 percent lived in urban areas outside reserves. The Inuit, who live primarily in rural communities, are the least urbanized of Aboriginal people, at 37 percent in urban areas. (Norris and Clatworthy 2011). 


\section{First Nations, Métis, and Inuit Populations with an Aboriginal Mother Tongue: 1996 and 2006}

In the 2006 Census, relatively high proportions of Inuit (63\%) and Registered Indians residing on-reserve (46\%) reported an Aboriginal mother tongue, compared to the more urbanized non-Status Indian (2.4\%) and Métis $(2.6 \%)$ identity populations (Figure 1 ). The same pattern was also observed in previous censuses, in 2001 (Norris 2006) and a decade earlier in 1996, with notably higher proportions of Inuit $(67 \%)$ and Registered Indians on reserves (52\%) reporting an Aboriginal mother tongue in contrast to 6 percent of non-Registered Indians and 8 percent of Métis (Norris 2003,99). However, since 1996, the share of the population with an Aboriginal mother tongue has seen a steady decline for all Aboriginal identity groups.

Over the past decade, the proportion of Aboriginal people reporting knowledge of, or the ability to speak, their traditional Aboriginal languages saw a decline from 29 percent in 1996 to 24 percent in 2001, and was down to 22 percent by 2006. Declines in the proportion able to speak an Aboriginal language have been most pronounced among the more urbanized nonStatus Indians and Métis (from 7\% and 8\% respectively in 1996 to about $3 \%$ each by 2006), with the least amount of decline occurring among the Inuit (from 74\% in 1996 to $71 \%$ in 2006). Registered Indians saw a drop in speakers from 37 percent in 1996 to 32 percent in 2001, and remained stable thereafter at 32 percent in 2006 (Figure 2). This decline among Registered Indians in the first half of the decade probably reflected, to some extent, the compositional effect of the continued impact at that time of the influx of new populations of reinstated Registered Indians (through the 1985 revisions to the Indian $\mathrm{Act}^{3}$ ), many of whom resided off-reserve and were less likely to speak Aboriginal languages than their counterparts who had Registered Indian status prior to 1985 .

\section{Impact of Population Growth of Aboriginal Identity Groups in Urban Areas, 1996-2006}

As noted earlier, caution is advised in the interpretation of declines in proportions reporting an Aboriginal language (as a mother tongue, home language, or ability to speak) as a consequence of the rapid growth of Aboriginal populations in urban areas over the 1996 to 2006 period (Guimond, Robitaille, and Senécal 2009, 11-17), especially among Métis. 


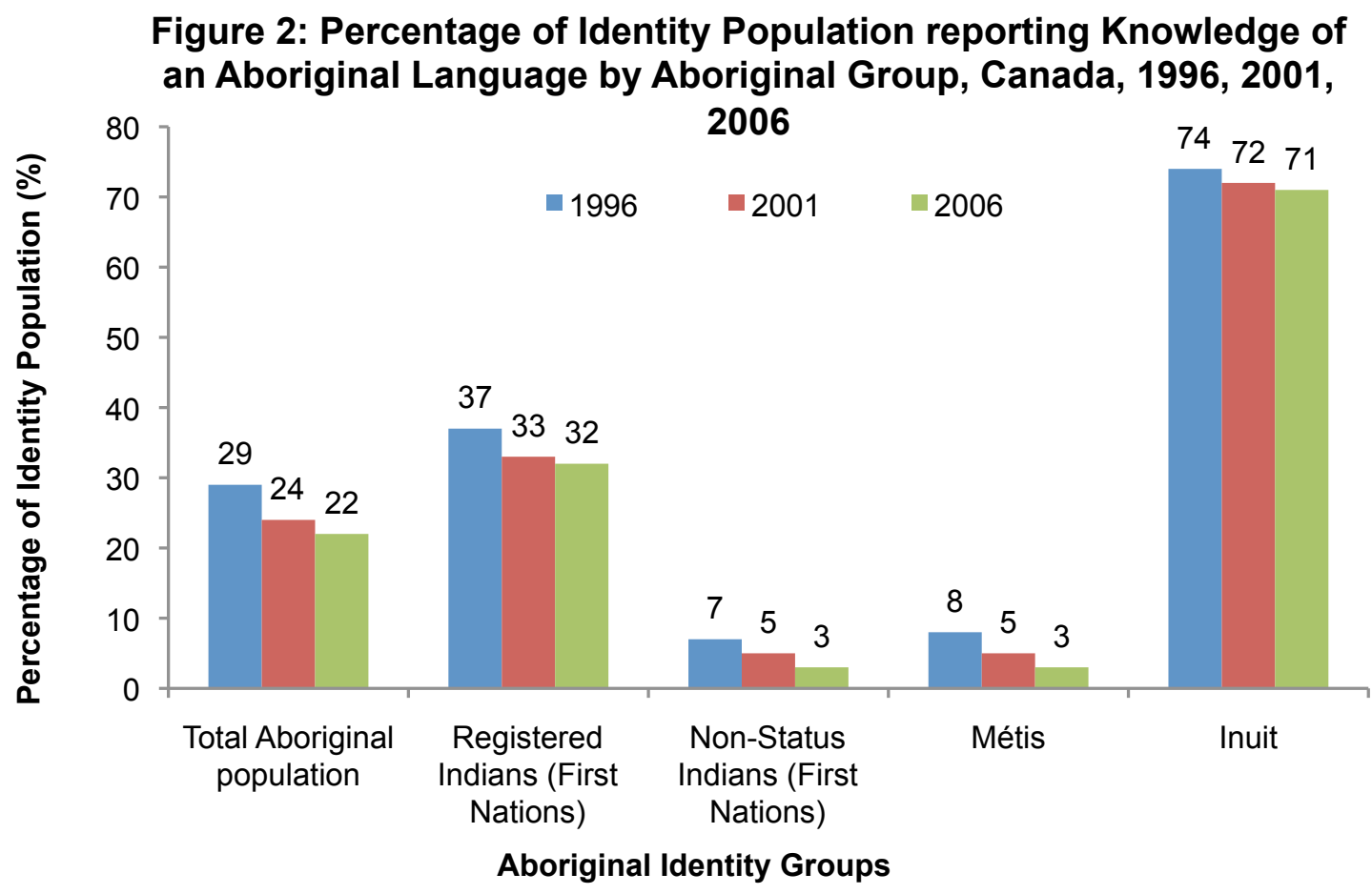

Source: 1996, 2001 and 2006 Census of Canada (unadjusted data)

The exceptional growth of the Métis population living in large cities, which doubled in size over the decade due largely to ethnic mobility, can have a significant impact on declining Métis proportions owing to the large increase in the population denominator.

First Nations, Métis, and Inuit Mother Tongue Populations by Place of Residence

The share of the Aboriginal population reporting a traditional language as a mother tongue varies significantly by residence, whether in Aboriginal communities, on reserves and settlements, in rural or urban areas, or in cities large or small. Similarly, as previous census-based research demonstrates, so do the chances of learning an Aboriginal language as a mother tongue or second language (or not at all) which vary by residence and family type. Children are most likely to acquire an Aboriginal mother tongue if they live in Aboriginal communities and in families where both parents have an Aboriginal mother tongue or first language. And, the research demonstrates the importance of place: in families where both parents are first language 
speakers, the proportions of children with an Aboriginal mother tongue are highest among those living on reserves $(68 \%)$ or in rural areas $(77 \%)$, but lowest in large cities at 41 percent. In large cities, chances are even less likely if only one of the parents has their traditional language as a first language, with just 10 percent of children having an Aboriginal mother tongue (Norris 2003, 63; 2006, 2009; Norris and MacCon 2003).

As with previous censuses, the 2006 data demonstrate significant variations in language characteristics by place of residence for each Aboriginal group, and the importance of Aboriginal communities - whether First Nations reserves, settlements and rural communities of Métis, and the northern communities of the Inuit-in supporting the maintenance and transmission of Aboriginal languages. Overall, for example, only 2.5 percent of Métis, similar to 2.4 percent of non-Registered Indians, report an Aboriginal language as their mother tongue, compared to 28 percent of Registered Indians and 66 percent of Inuit. However, among Métis living on "reserves and settlements" (settlements include some, but not all Métis communities), a much larger share, 14 percent, reported an Aboriginal mother tongue, in sharp contrast to just 1 percent of Métis residents in large cities (urban CMAs). Other off-reserve locations saw somewhat higher proportions at about 5 percent in rural areas (which also include some Métis communites) and close to 2 percent in smaller cities (urban non-CMAs) (see Figure 3).

Among other Aboriginal groups, despite considerable differences in levels, the effect of residence is somewhat similar, with the highest proportions reporting an Aboriginal mother tongue in Aboriginal communities (on reserves $46 \%$ of Registered Indians and $20 \%$ of nonRegistered Indians; in rural areas $75 \%$ of Inuit); and lowest proportions in large cities with corresponding proportions of 9 percent, 1 percent, and 19 percent respectively (Figure 3).

\section{First Nation, Métis, and Inuit Composition of Speakers Living in Urban Places}

In 2006, Registered Indians accounted for the vast majority, 80 percent, of the 219,000 Aboriginal people in Canada who reported an Aboriginal language as their mother tongue, followed by 15 percent Inuit, 4 percent Métis, and about 1 percent non-Registered Indians. Registered Indians living on-reserve made up the majority of the identity population, at almost 


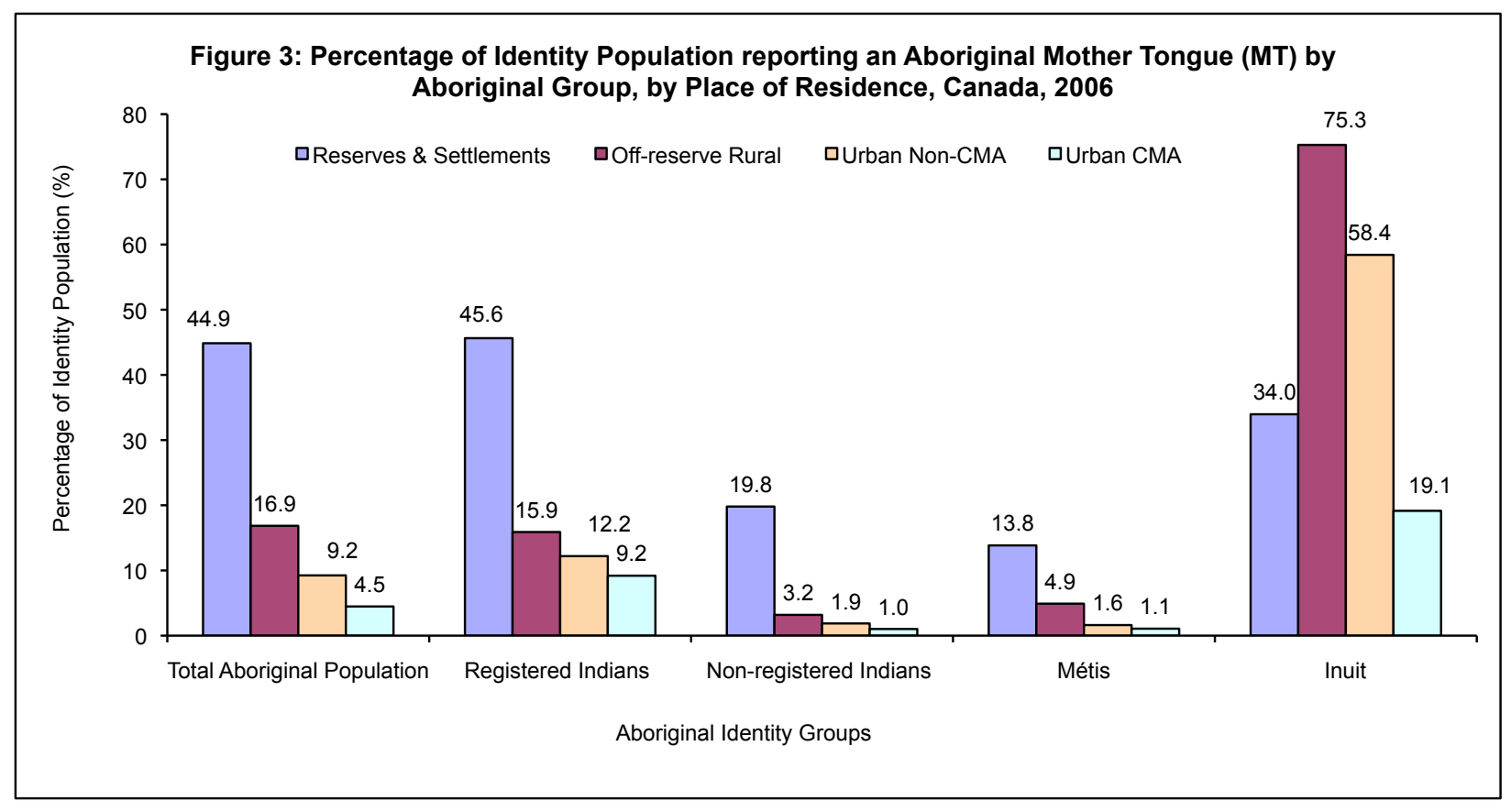

Source: 2006 Census of Canada (unadjusted data)

two-thirds (63\%) of those who reported an Aboriginal mother tongue in 2006; and it would appear, had a larger share than their previous 58 percent of the Aboriginal mother tongue population a decade ago (Norris 2003, 99). As a consequence of group differences in language characteristics, residential distributions, and migration patterns, the First Nation, Métis, and Inuit composition of mother tongue populations varies significantly by residence (Figure 4a), and can also contrast sharply with the group composition of Aboriginal identity total populations (Figure 4b). Registered Indians and Inuit, together accounting for the vast majority (95\%) of the Aboriginal mother tongue population, clearly represent disproportionately high shares, at 80 percent and 15 percent respectively, in comparison to their corresponding shares of the total Aboriginal identity population of 54 percent and 4 percent. Conversely, Métis and non-Registered Indians shares of the Aboriginal mother tongue population, at just 4 percent and 1 percent respectively, are disproportionately low in comparison to their corresponding shares of the total Aboriginal identity population of 31 percent and 11 percent.

Similar comparisons can also be observed by place of residence. For example, in large cities (urban CMAs), the Aboriginal mother tongue population and the total identity population contrast sharply in their 


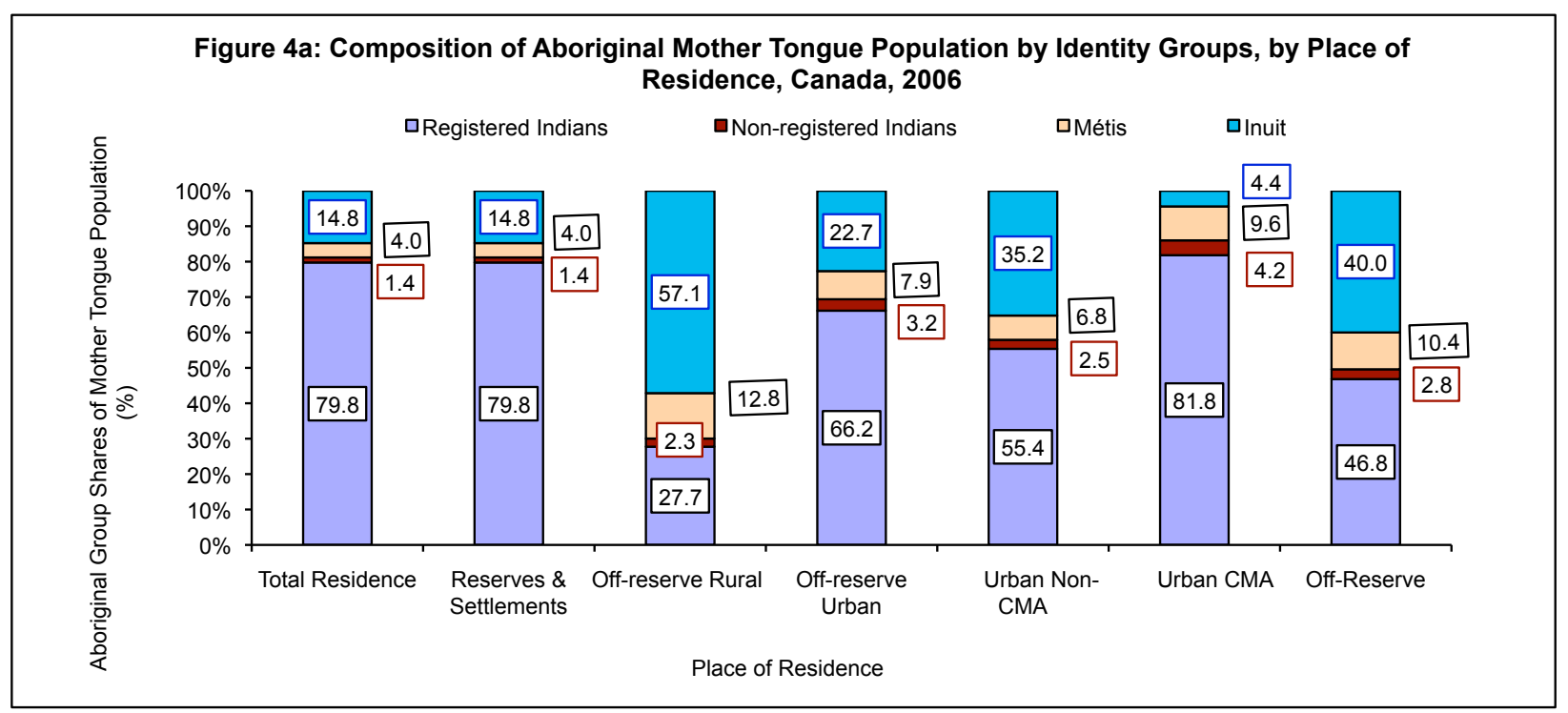

Source: 2006 Census of Canada (unadjusted data)

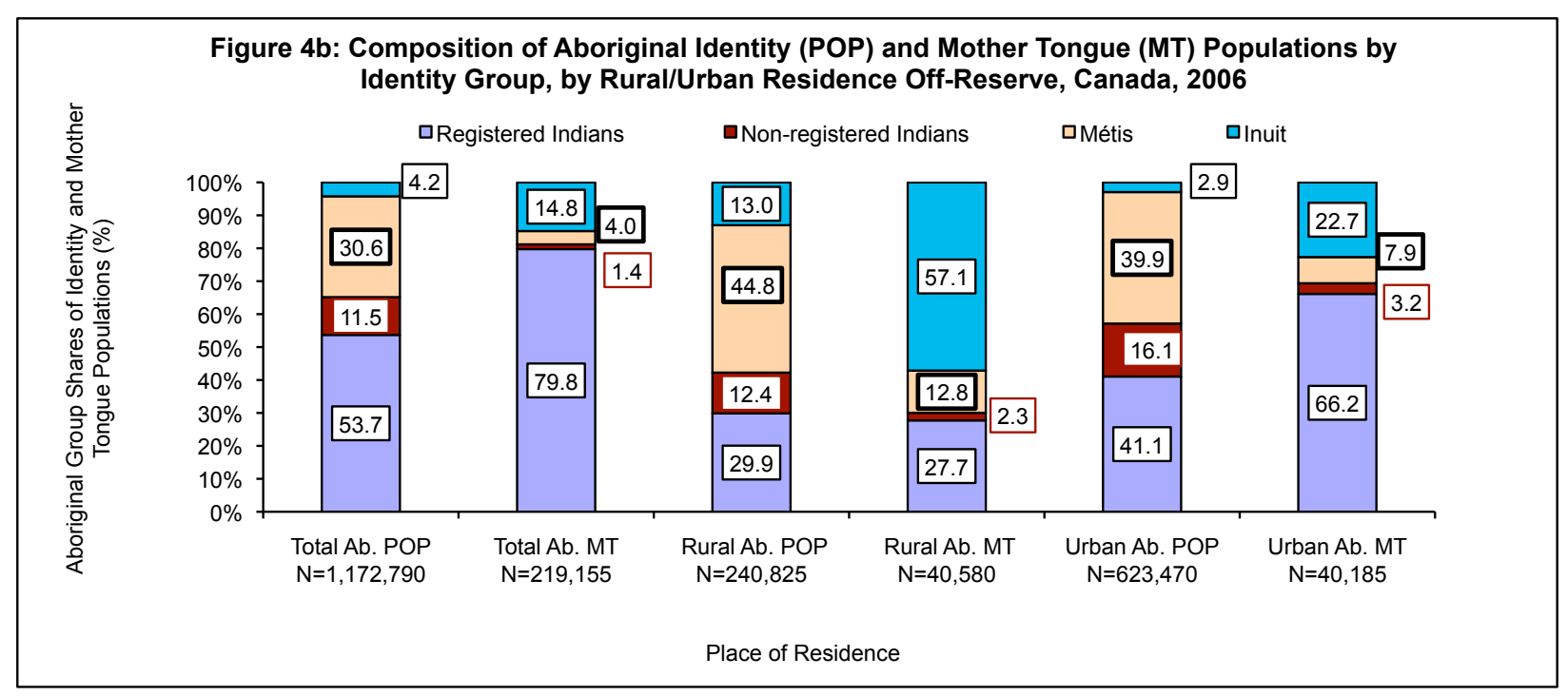

Source: 2006 Census of Canada (unadjusted data) 
Aboriginal group composition. Both Métis and Registered Indians account for the largest shares of the Aboriginal identity population in urban CMAs, at about 40 percent each. However, in comparison, Métis account for a disproportionately low share of the Aboriginal mother tongue population, at just 10 percent, with Registered Indians representing the vast majority, with the disproportionally high share of 82 percent of the mother tongue population (Figure 4a).

Contrasts in Aboriginal group composition between the Aboriginal identity and Aboriginal mother tongue population are shown by place of residence for reserves and settlements, and rural and urban areas off-reserve in Figure 4b. Outside of reserves in rural areas, which include other some of the Inuit and Métis communities, patterns of contrasts in composition differ. The proportion of Registered Indians comprising the Aboriginal mother tongue population in rural areas $(28 \%)$ is proportionate, and practically the same as their share $(30 \%)$ of the total rural Aboriginal population. On the other hand, the Inuit, who make up 13 percent of the Aboriginal population in rural areas, account for well over half (57\%) of the Aboriginal mother tongue in rural areas. The Métis share of the Aboriginal mother tongue population is at its highest in rural areas accounting for 13 percent of rural first language speakers, though (again) this share is also disproportionately low, given that Métis make up 45 percent of the rural Aboriginal identity population (Figure 4b). From another perspective, $2006 \mathrm{Census} \mathrm{data} \mathrm{indicate}$ that 69 percent of the total Métis population lives in urban areas, but among the Métis who report an Aboriginal mother tongue, only 36 percent reside in urban areas. Off-reserve, while the rural/urban split of the total Métis identity population is $30: 70$, it is almost the reverse, at 62:38, for the Métis Aboriginal mother tongue population.

\section{Aboriginal Language Demographics: Transmission, Use, and Learning}

\section{Size and Transmission Critical}

The transmission of a language from one generation to the next and population size are both important considerations in the viability of a language. While many Aboriginal languages today have fairly small mother tongue populations of less than a thousand speakers, some of the languages associated with the larger Cree, Inuktitut, and Ojibway groups are thought to have sufficiently large population bases for long-term language survival (Kinkade 1991, 163) These languages, and even some smaller languages that 
have a high ratio of a home speakers to their mother tongue population, are highly likely to be passed on to the next generation. The use of a language as a "major" language in the home has important implications for the prospects of transmission to the next generation and, hence, its continuity. A language no longer spoken "most often" at home is not likely to be handed down as a mother tongue to the younger generation. Inuktitut has relatively high continuity, with an index in 2006 of 79 persons speaking Inuktitut at home for every 100 with an Inuktitut mother tongue, followed by indexes of 62 and 47 for Cree and Ojibway, respectively; these three languages have been classified as relatively viable (Table 1).

In sharp contrast, many of the smaller languages, which often have far fewer than a thousand speakers (especially in British Columbia), have very low prospects for continuity and can be considered endangered. As of 2006 , for example, there were only 125 persons with a Haida mother tongue, and a continuity index of only 16 . On the other hand, even with only a few thousand people, some of the smaller languages elsewhere in Canada appear viable when home usage is taken into account. The Attikamek language in Quebec, which has a mother tongue population of only 5,400 persons, has a continuity index of 92 . Other small-sized languages such as Montagnais and Naskapi, Micmac, Dene, and Dogrib are considered viable, tending to be spoken in isolated or well-organized communities with strong selfawareness, and where language is considered one of the important marks of identity (Kinkade 1991).

\section{Stage of Life Affects Home Use of Aboriginal Languages}

A cohort analysis of past census data (1981-1996) demonstrates that the use of an Aboriginal language at home relative to the mother tongue population is related to stages in life. For example, the decline in home language usage is significant as youth leave home and enter the labour force, marry, start families, or move to a larger urban environment, especially for women. Women are more likely than men to leave their reserves and move to other locations where the chances of marrying non-Aboriginals are higher and where the exposure to the dominant language is much greater as well (Norris 1998). Furthermore, linguistic intermarriage, more prevalent in larger urban populations, poses challenges to transmitting Aboriginal language as a mother tongue, especially among endangered languages that are characterized by a high occurrence of mixed marriages (Table 1). Children in mixed marriages (Aboriginal-non-Aboriginal languages), 
however, are much less likely to have an Aboriginal mother tongue than children in marriages where both parents have an Indigenous mother tongue (Norris 2003, 2009; Norris and MacCon 2003).

\section{Home Language Use: Spoken On a "Most Often" or a "Regular" Basis}

The distinction between Aboriginal home language use on a "most often" versus a "regular" basis provides new insight into the patterns of Aboriginal language use within the home. The aspect of "regular" home use is especially relevant for speakers of endangered languages or city residents, who face considerable challenges in maintaining an Aboriginal language as the major home language, but yet may be able to at least speak it on a regular basis in the home. For example, in 2006, the vast majority of people speaking some of the larger and more viable languages at home, like Inuktitut and Cree, reported them as the language spoken "most often" in the home, at 80 percent and 81 percent respectively. However in the case of endangered languages, only a minority of home language users report their language as spoken "most often" - such as Haida, at only 33 percent.

Similarly, residence within or outside Aboriginal communities can impact the extent to which traditional languages are spoken in the home: among the 125,500 persons residing on reserves who report an Aboriginal home language in 2006, 95,700 or 76 percent, speak it on a "most often" basis; while the other 24 percent speak it not as a major language, but at least "regularly" (Table 2b). The pattern is practically reversed in cities outside of reserves, where only 37 percent of respondents who report home use speak an Aboriginal language "most often" while the vast majority, 63 percent, speaks an Aboriginal language "regularly."

\section{"Young" and "Old" Languages}

The average age of those who have an Aboriginal mother tongue or speak it as a home language indicates the extent to which the language has been transmitted to the younger generation. The higher the average age, the relatively fewer young people have learned or still understand the language and the older the people who still speak it. If the language is not transmitted to the younger generations then, as these older persons continue to age and then die, so will the language. Viable languages such as Attikamek, Inuktitut, and Dene are characterized by relatively young mother tongue populations (average ages between 25 and 29 years) and corresponding high indexes of continuity (between 79 and 92) In contrast, endangered languages such as 
Haida, Kutenai, and Tlingit have typically older mother tongue populations (average ages between 45 and 60) combined with extremely low continuity indexes of 16 or less (Table 1).

In general, the population with an Aboriginal mother tongue is older than the overall Aboriginal population: in 2006 the average age of Aboriginal people reporting an Aboriginal language as a mother tongue was 34 years, compared to an average age of just 29 years overall. Children and youth (those under the age of 25) represent almost half -48 percent - of the total Aboriginal population, yet account for only 39 percent of the mother tongue population. Older Aboriginal adults are much more likely to have an Aboriginal mother tongue than younger generations-only some 15 percent of children and youth reported an Aboriginal mother tongue, compared to about a quarter of those aged 45 to 64 , and a third of those 65 years old.

\section{A Second Language Instead of a Mother Tongue}

As noted earlier, although younger generations may not be learning their Indigenous language as a mother tongue, it appears they are at least learning it as a second language, as evidenced by the "Ability" or "Second Language" Index. For example, the isolate of Kutenai has one of the smallest and oldest mother tongue populations at 95 persons (average age 60), along with one of the lowest continuity indexes (11). However, the second language index of 189 and an average age of 45 among all speakers both suggest that for every person with a Kutenai mother tongue there are almost two people (generally younger) who are able to speak it. This suggests that younger generations are more likely than older generations to learn Kutenai as a second language than as a mother tongue (Table 1). These second language patterns are even more pronounced off-reserve and in cities, especially among the younger generations (Norris 1998, 2007, 2008, 2009; Norris and Jantzen 2003; Norris and Snider 2008).

\section{Aboriginal Language Demographics in Urban Areas, 1996 and 2006}

The demographics of Aboriginal languages in urban areas remained relatively the same over the decade between 1996 and 2006. However, contrasts between speakers and non-speakers, and urban and non-urban areas, in some patterns of residential distributions, age composition, language use, and first and second language composition of speakers appear more pronounced ten years later, in 2006. As noted, various factors can contribute 
to changes in speaker composition, measures, and indicators in urban areas, such as the impact of population growth, migration, natural increase, and changes in language acquisition, intergenerational transmission, or second language learning. Also, 1996 and 2006 census data have not been adjusted for intercensal differences in coverage.

The analysis of patterns presented here for both the 1996 and 2006 Censuses is based on a five-category geographic classification employed in the 1996 Census study. A four-category geographic classification is used with 2006 Census data only, mainly for those measures not analyzed in the previous 1996 Census study, including "most frequent" and "regular" home language use, and detailed cross-classifications of language patterns by age and residence.

\section{Residential Distributions of Populations with Aboriginal Mother Tongue or Language Knowledge By On/Off-Reserve and City (CMA\&CA) Place of Residence, 1996 and 2006}

Aboriginal people reporting an Aboriginal mother tongue and/or the ability to speak an Aboriginal language are much less urbanized than the identity population overall, being more likely to reside on reserves or outside cities as compared to the Aboriginal population in general. In 2006, out of the 219, 200 Aboriginal people reporting an Aboriginal language as their mother tongue, about 28,000 resided in cities outside of reserves (CMA and CAs excluding reserves within their boundaries), while the vast, majority, some 191,300 , resided in areas outside of cities, with most of them $(138,400)$ on reserves (Table 2a, Figures 5 and 6a).

Trends between 1996 and 2006 suggest that the contrast in residential distributions between speakers and non-speakers of Aboriginal languages has become more pronounced over the decade, particularly in relation to cities. Over that time, the residential distribution of the Aboriginal population overall became more urbanized, which is, in part, a reflection of the effects of high ethnic mobility in urban areas. In contrast, the distribution of speakers has become less urbanized, with a shift towards areas outside of cities, including reserves. In Canada in 1996, 48 percent of the population who reported an Aboriginal identity resided in cities (CMAs and CAs), ${ }^{4}$ or some 382,000 people, of whom about 21,000 were living on reserves within city boundaries. By 2006, the population in cities increased to some 605,000 people (with about 22,000 living on reserves), and accounted for 
Figure 5: Residential Distributions of Aboriginal Populations reporting an Aboriginal Mother Tongue or Language Knowledge by Place of Residence On and Off Reserve, Canada, 1996, 2006

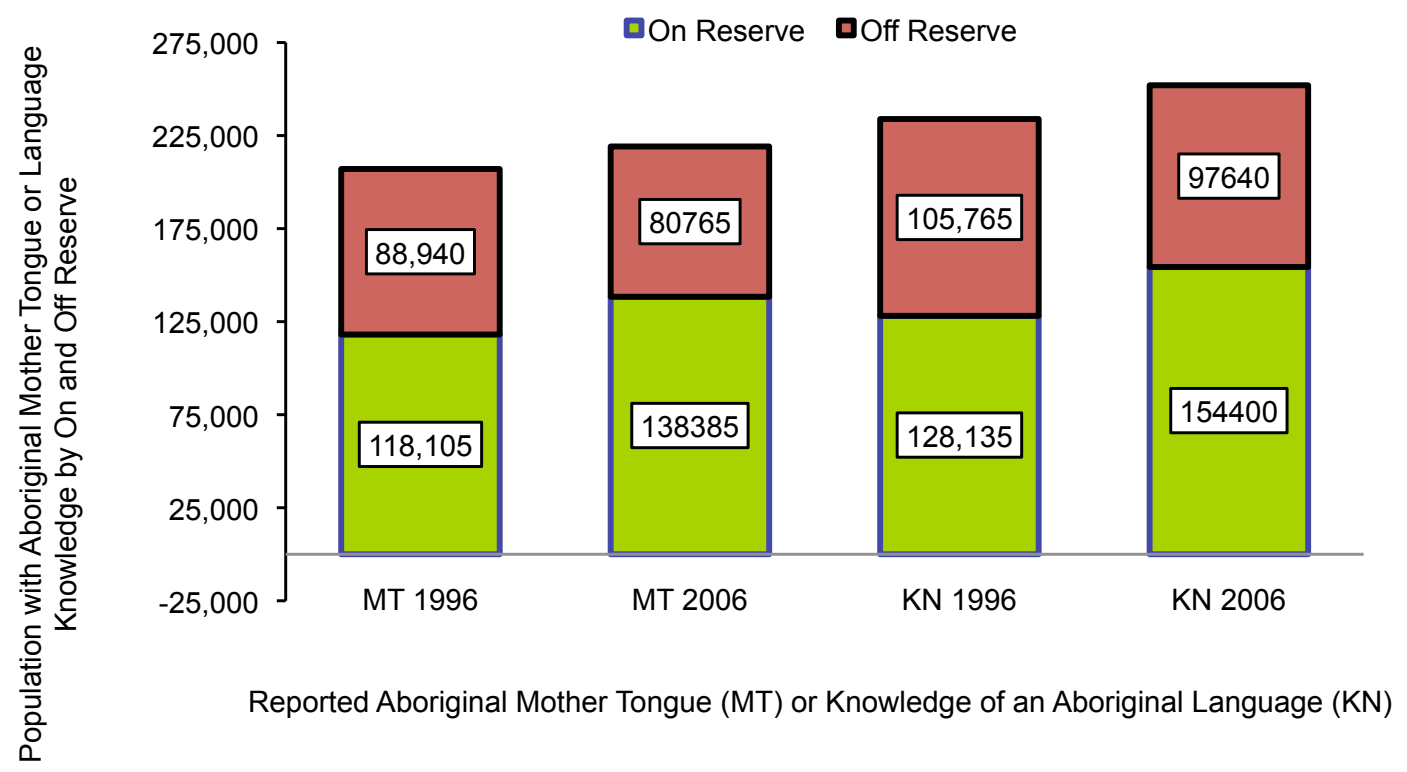

Source: 1996 and 2006 Census of Canada (unadjusted data)

Figure 6a: Residential Distribution of Aboriginal Populations reporting an Aboriginal Mother Tongue or Language Knowledge by Residence Within/ Outside Cities (CMA\&CA), Canada, 1996, 2006

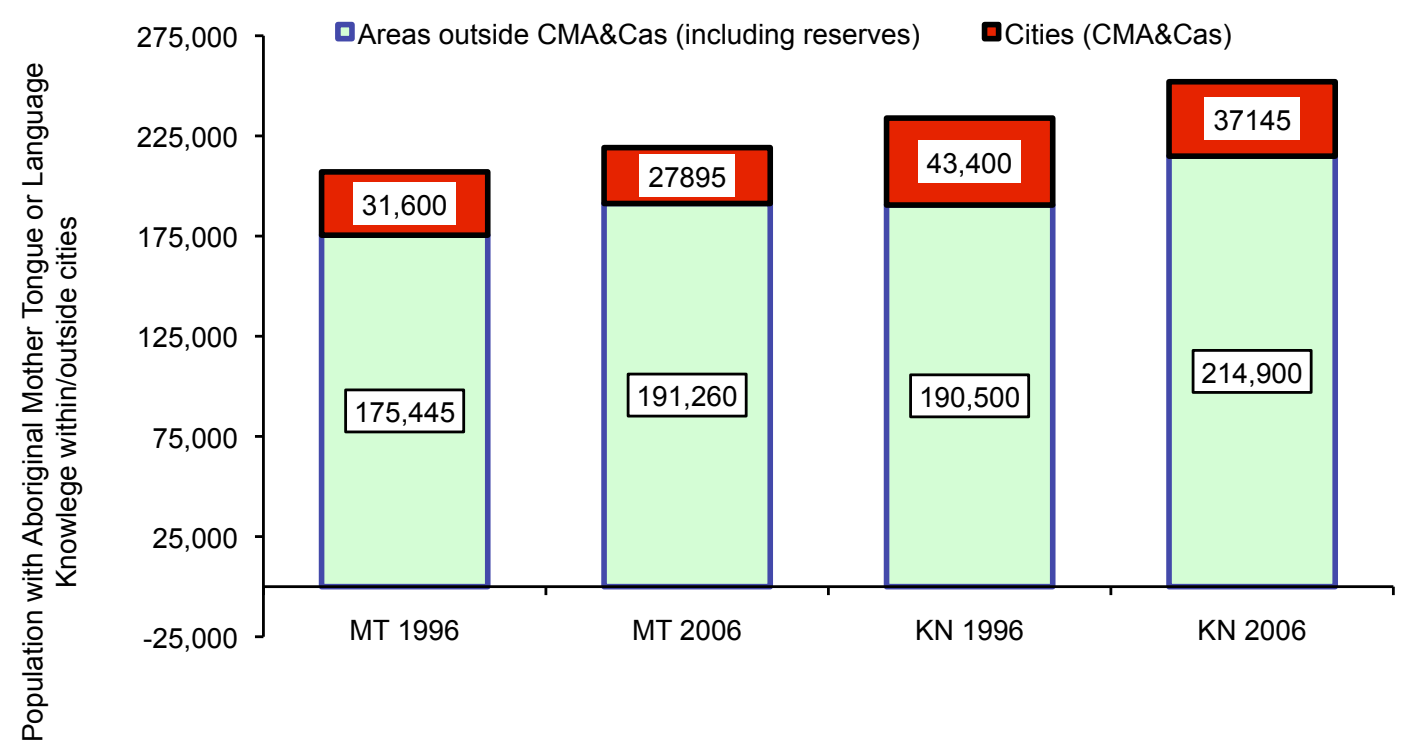

Reported Aboriginal Mother Tongue (MT) or Knowledge of An Aboriginal Language (KN)

Source: 2006 Census of Canada (unadjusted data) 
53 percent of the enumerated 1.17 million Aboriginal identity population. Corresponding city shares that exclude reserves within CMA and CA boundaries are somewhat lower, at 45 percent in 1996 and 51 percent in 2006.

While the share of urban dwellers within the Aboriginal population increased by the end of the decade, the corresponding urban shares of populations with an Aboriginal mother tongue or language knowledge decreased between 1996 and 2006. In 1996, 15 percent of the population reporting an Aboriginal mother tongue, and 19 percent of the population reporting the ability to speak an Aboriginal language, resided in cities (excluding reserves). By 2006, the mother tongue population of 28,000 Aboriginals in cities (excluding reserves) accounted for a lower share, 13 percent, of the total Aboriginal population reporting an Aboriginal mother of 219,000. Similarly, a lower share, 15 percent or 37,000 of the 252,000 Aboriginal people able to speak an Aboriginal language, lived in cities (Table 2a). These trends suggest higher growth of the populations with an Aboriginal mother tongue or ability to speak an Aboriginal language in areas outside of cities, particularly in Aboriginal communities and reserves. Further distinctions for 2006 in residence by rural areas and small and large cities (with cities excluding rural areas as well as reserves), indicate that 8 percent of the Aboriginal population reporting an Aboriginal mother tongue and 9 percent reporting the ability to speak an Aboriginal language in Canada reside in large cities (urban CMAs) (Table 2b).

\section{Home Language Speakers: Residential Distributions of "Most Often" or "Regular" Use}

The population speaking an Aboriginal language "most often" at home, as their major home language, is also much more likely to be living on reserves or outside cities as compared to the Aboriginal population in general, and as observed with the mother tongue and knowledge populations, has seen a shift away from cities. In 1996, city residents made up only 7 percent of the 145,400 Aboriginal persons who reported an Aboriginal language as their major language at home; by 2006, city residents accounted for an even lower share, at 5 percent of the corresponding 138,200 individuals who reported speaking their traditional language at home on a "most often" basis (Table 2a, Figure 6b). 
Figure 6b: Residential Distribution of Aboriginal Populations reporting an Aboriginal Home Language Spoken on a "Regular" or "Most Often" basis, Within/Outside Cities and On/Off Reserve, Canada 2006

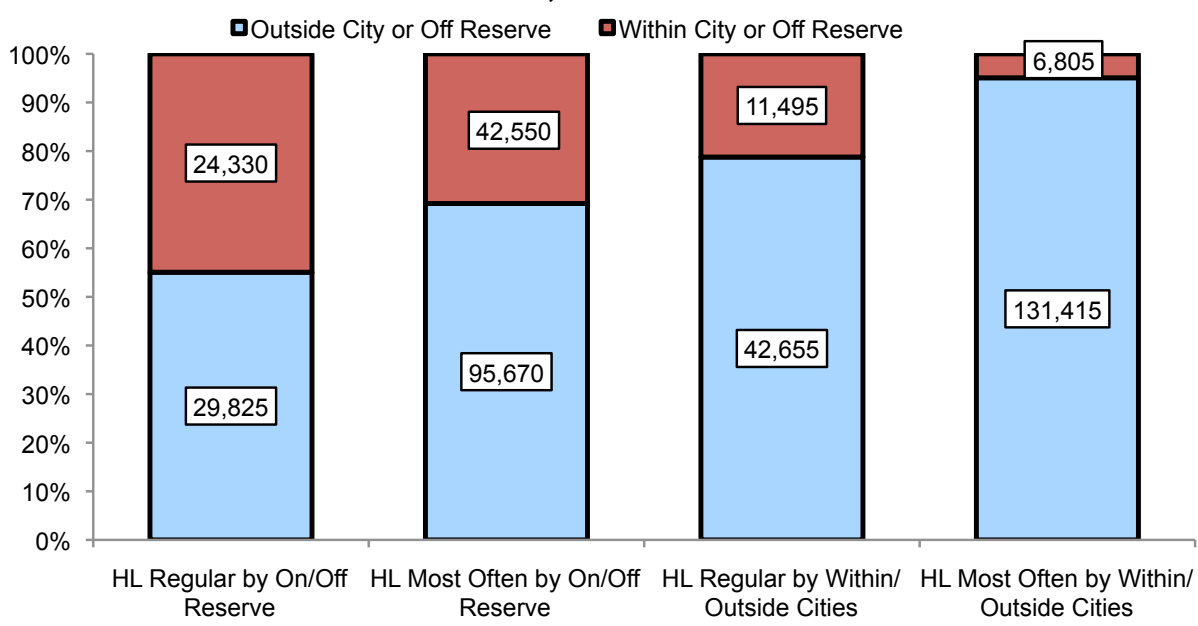

Home language $(\mathrm{HL})$ Spoken on a "Regular" or "Most Often" Basis, Within/Outside Cities (CMAs\&CAs) and by On/Off Reserve

Source: 2006 Census of Canada (unadjusted data)

However, with respect to speaking an Aboriginal home language at least on a "regular" basis, it appears from both the 2001 and 2006 Censuses (data not available for 1996) that city residents are much more likely to speak their Aboriginal language at home on a "regular" than on a "most often" basis. In 2006, a total 18,300 Aboriginal residents in cities (excluding reserves) reported speaking an Aboriginal language at home, on either a "regular" or "most often" basis. The majority (63 percent, or 11,500 persons) of urban Aboriginal residents reporting home use spoke their Aboriginal language on a "regular" basis, while the other 37 percent $(6,805)$ spoke their Aboriginal language on a "most often" basis (in 2001 the proportion of "regular" home use speakers was 59\%) (Figure 6b). What is most notable, though, is the significant difference in residential distributions between "regular" and "most often" speakers. In 2006, city residents accounted for about one in five (21\%) of the 54,150 Aboriginal people across Canada who spoke their Aboriginal language at home on a "regular" basis, compared to only one in 20 persons (5\%) of the 138,200 persons speaking an Aboriginal language "most often" at home. Conversely, but in a less pronounced fashion, reserve residents account for less than half (45\%), of "regular" home users as compared to the vast majority, about 
70 percent, of speakers using an Aboriginal language as the major home language (Figure 6b). Further distinctions between small and large cities in 2006 reveal more pronounced differences between home language use on a regular and most often basis in large cities. In 2006, less than half, or about 47 percent of the 19,200 Aboriginal residents in small cities (urban non-CMAs) reporting home language use, spoke their Aboriginal language on a "regular" basis, whereas, practically two-thirds $(65 \%)$ of the 10,200 residents residing in larger cities who spoke an Aboriginal language at home spoke it on a "regular" basis. Residents in large cities accounted for about 12 percent of the 54,150 Aboriginal people in Canada who speak their Aboriginal language at home on a "regular' basis, compared to only 3 percent of the 138,200 persons speaking an Aboriginal language "most often" at home (Table 2b).

From the viewpoint that the transmission of an Aboriginal language as a mother tongue through major home use is especially difficult in urban areas, the finding that people are at least using an Aboriginal language on a "regular" basis, even if not as their major home language, and rather than not at all is somewhat encouraging for language learning prospects in urban areas. While it is reasonable to assume that the language that is used "most often" at home would still most likely be the one transmitted to the next generation, "regular" use in the home may, nevertheless, go some way towards slowing down Aboriginal language loss. It may also, perhaps, contribute to language maintenance to some extent, and may even more likely be a significant contributor to learning an Aboriginal language as a second language.

\section{Propensity to Learn and Speak an Aboriginal Language by Place of Residence}

Both the 1996 and 2006 Censuses show that urban Aboriginal people are considerably less likely to report an Aboriginal mother tongue or an ability to speak an Aboriginal language than those living in Aboriginal or reserve communities. In the 2006 Census, only 5 percent of the 576,400 Aboriginal people residing in cities (CMAs and CAs excluding reserves) reported an Aboriginal mother tongue, while a slightly higher percent, 6 percent, indicated the ability to speak an Aboriginal language, which certainly is significantly lower than the corresponding proportions of $45 \%$ and $50 \%$, respectively, for the Aboriginal population living on reserves (Table 3a). 
Prospects of first and second language speakers of Aboriginal languages are lowest in large cities, where only 4 percent of Aboriginal residents in 2006 reported an Aboriginal mother tongue or first language, and 6 percent the ability to speak an Aboriginal language, including second language speakers (Table 3b).

The greatest gap between Aboriginal language speakers within and outside cities in terms of language use is in the home. In 2006, some 6,800, or just 1 percent, of Aboriginal city residents (in CMA and CA cities and in large urban CMA cities) reported an Aboriginal language as one spoken most often in the home, compared to 22 percent of the population residing outside of cities, 31 percent on-reserve, and 12 percent overall (Tables 3a and $3 \mathrm{~b}$ ). However, even though an Aboriginal language may not be a major language in the home, it can still be spoken on a "regular" basis. In addition to the 31 percent of people on reserves who speak their traditional language at home "most often," for example, another 10 percent speak their language on a "regular" basis at home. Among city residents (in CMA and CA cities and in large urban CMA cities), an additional 2 percent report speaking an Aboriginal language at home on at least a regular basis, twice the proportion speaking it as a major home language (Tables $3 \mathrm{a}$ and $3 \mathrm{~b}$ ).

\section{Residential Trends in Cities Over the Past Decade}

Aboriginal populations reporting an Aboriginal mother tongue or the ability to speak an Aboriginal language increased in Canada over the decade, particularly outside of cities. However, they appear to have decreased within cities (CMAs and CAs), from a mother tongue (first language) population of 32,000 to 28,000 , and similarly from 43,000 to 37,000 speakers (both first and second language combined). The decrease in corresponding proportions was much more pronounced over the period, dropping from 12 percent of city residents able to speak an Aboriginal language in 1996 to just 6 percent of residents ten years later (Table $2 b$ ). The significant growth of the Aboriginal identity population in cities from some 360,600 persons in 1996 to 576,400 by 2006 (Table 2a), largely due to ethnic mobility, was a significant factor in these pronounced declines.

Both 1996 and 2006 findings demonstrate that language trends and characteristics of Aboriginal populations, whether in population change, patterns of language acquisition, speaker composition, or home useclearly vary by place of residence. 
Table 3a: Percentage of Aboriginal Identity Population with Aboriginal Mother Tongue, Home Language, or Knowledge by On/Off-Reserve and City (CMA\&CA) Place of Residence, Canada, 1996 and 2006 Census

\begin{tabular}{|c|c|c|c|c|c|c|}
\hline \multirow[b]{2}{*}{$\begin{array}{l}\text { Language } \\
\text { Variables }\end{array}$} & \multirow[b]{2}{*}{$\begin{array}{c}\text { Canada- } \\
\text { Total } \\
\text { Residence } \\
(1)\end{array}$} & \multicolumn{5}{|c|}{ Place of Residence } \\
\hline & & $\begin{array}{c}\text { On-Reserve } \\
\text { (2) }\end{array}$ & $\begin{array}{c}\text { Off-Reserve } \\
\text { (3) }\end{array}$ & $\begin{array}{c}\text { Cities - CMA/CAs } \\
\text { (includes reserves } \\
\text { within CMA/CA } \\
\text { boundaries) } \\
\text { (4) }\end{array}$ & $\begin{array}{c}\text { Cities - CMA/CAs } \\
\text { (not including } \\
\text { smaller urban areas) } \\
\text { Adjusted } \\
\text { (excludes reserves } \\
\text { within CMA/CA } \\
\text { boundaries) } \\
(5)\end{array}$ & $\begin{array}{c}\text { Population } \\
\text { Outside } \\
\text { CMA/CAs } \\
\text { (includes reserves } \\
\text { within CMA/CA } \\
\text { boundaries) } \\
(6)=(1)-(5)\end{array}$ \\
\hline \multicolumn{7}{|c|}{1996 Census } \\
\hline Mother Tongue & $26 \%$ & $51 \%$ & $16 \%$ & $10 \%$ & $9 \%$ & $40 \%$ \\
\hline Home Language & $18 \%$ & $41 \%$ & $9 \%$ & $4 \%$ & $3 \%$ & $31 \%$ \\
\hline Knowledge & $29 \%$ & $55 \%$ & $19 \%$ & $14 \%$ & $12 \%$ & $43 \%$ \\
\hline \multicolumn{7}{|c|}{2006 Census } \\
\hline Mother Tongue & $19 \%$ & $45 \%$ & $9 \%$ & $7 \%$ & $5 \%$ & $32 \%$ \\
\hline Home Language & $12 \%$ & $31 \%$ & $5 \%$ & $3 \%$ & $1 \%$ & $22 \%$ \\
\hline Knowledge & $21 \%$ & $50 \%$ & $11 \%$ & $9 \%$ & $6 \%$ & $36 \%$ \\
\hline
\end{tabular}

Source: 1996 and 2006 Census of Canada (unadjusted data)

Table 3b: Percentage of Aboriginal Identity Population with Aboriginal Mother Tongue, Home Language, or Knowledge by On-Reserve, and Off-Reserve Rural, Urban non-CMA, and Urban CMA Place of Residence, Canada, 2006 Census

\begin{tabular}{|c|c|c|c|c|c|c|c|}
\hline Language Variables & Canada-Total residence & On-reserve & $\begin{array}{l}\text { Total } \\
\text { Off- } \\
\text { reserve }\end{array}$ & Rural & Urban & $\begin{array}{l}\text { Urban Non-CMAs } \\
\text { (small cities) } \\
\text { (including smaller } \\
\text { urban areas) }\end{array}$ & $\begin{array}{l}\text { Urban } \\
\text { CMAs (large } \\
\text { cities) }\end{array}$ \\
\hline Mother Tongue & $19 \%$ & $45 \%$ & $9 \%$ & $17 \%$ & $6 \%$ & $9 \%$ & $4 \%$ \\
\hline Home Language: Most Often & $12 \%$ & $31 \%$ & $5 \%$ & $12 \%$ & $2 \%$ & $4 \%$ & $1 \%$ \\
\hline Home Language: Regular & $5 \%$ & $10 \%$ & $3 \%$ & $4 \%$ & $3 \%$ & $3 \%$ & $2 \%$ \\
\hline Knowledge & $21 \%$ & $50 \%$ & $11 \%$ & $19 \%$ & $8 \%$ & $12 \%$ & $6 \%$ \\
\hline Total Aboriginal Population & $1,172,790$ & 308,495 & 864,295 & 240,825 & 623,470 & 257,305 & 366,165 \\
\hline \multicolumn{8}{|c|}{$\begin{array}{l}\text { Included in the Aboriginal population are those persons who reported identifying with at least one Aboriginal group, i.e., North } \\
\text { American Indian, Métis or Inuit (Eskimo) and/or who reported being a Treaty Indian or a Registered Indian as defined by the Indian } \\
\text { Act of Canada and/or who reported they were members of an Indian Band or First Nation. } \\
\text { Source: } 2006 \text { Census of Canada (unadjusted data) }\end{array}$} \\
\hline
\end{tabular}

\section{Mother Tongue (First Language) and Second Language Speakers: Patterns of Language Acquisition and Speaker Composition by Place of Residence}

Among Aboriginal people who can speak an Aboriginal language, census data over the past decade suggest that those residing in cities, compared to speakers living outside cities in Aboriginal communities and on reserves, are much less likely to have learned their traditional language as a mother tongue, and are more likely than those in communities to have acquired their traditional language as a second language. In 2006, only 24 persons in cities spoke an Aboriginal language at home for every 100 persons with an Aboriginal mother tongue, as compared to 69 home language speakers among the Registered Indian on-reserve population (Figure 7). As well, 
for every 100 persons in cities who reported an Aboriginal mother tongue, 133 persons indicated they were able to speak an Aboriginal language. In contrast, among persons residing in areas outside cities and on reserves specifically, the second language index was much lower at 112 (Figure 8). Among Registered Indians on reserves, the number reporting an ability to speak the language is even closer to 100 , since the vast majority, or practically all who can speak their traditional language, typically learned it as a mother tongue (first language).

Variations in the first and second language composition of speakers and related patterns of language acquisition by place of residence have remained remarkably similar over the decade, although actual levels have changed overall. Language continuity - that is, home use of an Aboriginal language relative to its mother tongue population-declined overall at the national level, from an index of 70 in 1996 to an index of 63 by 2006 . This pattern of decreased continuity was observed across all places of residence, on and off-reserve, within and outside cities in continuity, reflecting the decreasing trend in the major use of Aboriginal languages everywhere within the home. The index of second language acquisition increased slightly for Canada over the decade, and among Aboriginal populations residing on reserves, off-reserve overall, and specifically in areas outside cities. However, within cities (CMA and CAs), the index decreased slightly, such that in 2006 there were relatively fewer people-133-able to speak an Aboriginal language for every 100 persons with an Aboriginal mother tongue in cities, compared to 137 in 1996 (Figure 8). However, caution is needed in interpreting this change over the decade in question, since it does not necessarily imply decreased acquisition of Aboriginal languages as second languages among urban residents, but could also reflect compositional shifts in the first and second language speaker populations due to the effects of migration and natural increase.

\section{Youth in Cities: Learning and Speaking Their Aboriginal Languages, 1996 and 2006}

The transmission of Aboriginal languages as a mother tongue or first language from parent to child is clearly jeopardized in an urban environment, with the relatively low use of Aboriginal languages as major languages in the homes of urban residents, especially among Aboriginal women in childbearing ages. This low level of traditional language use as primary home languages 
Figure 7: Index of Aboriginal Language Continuity, by On/Off Reserve and Within/Outside City Place of Residence, Canada, 1996 and 2006

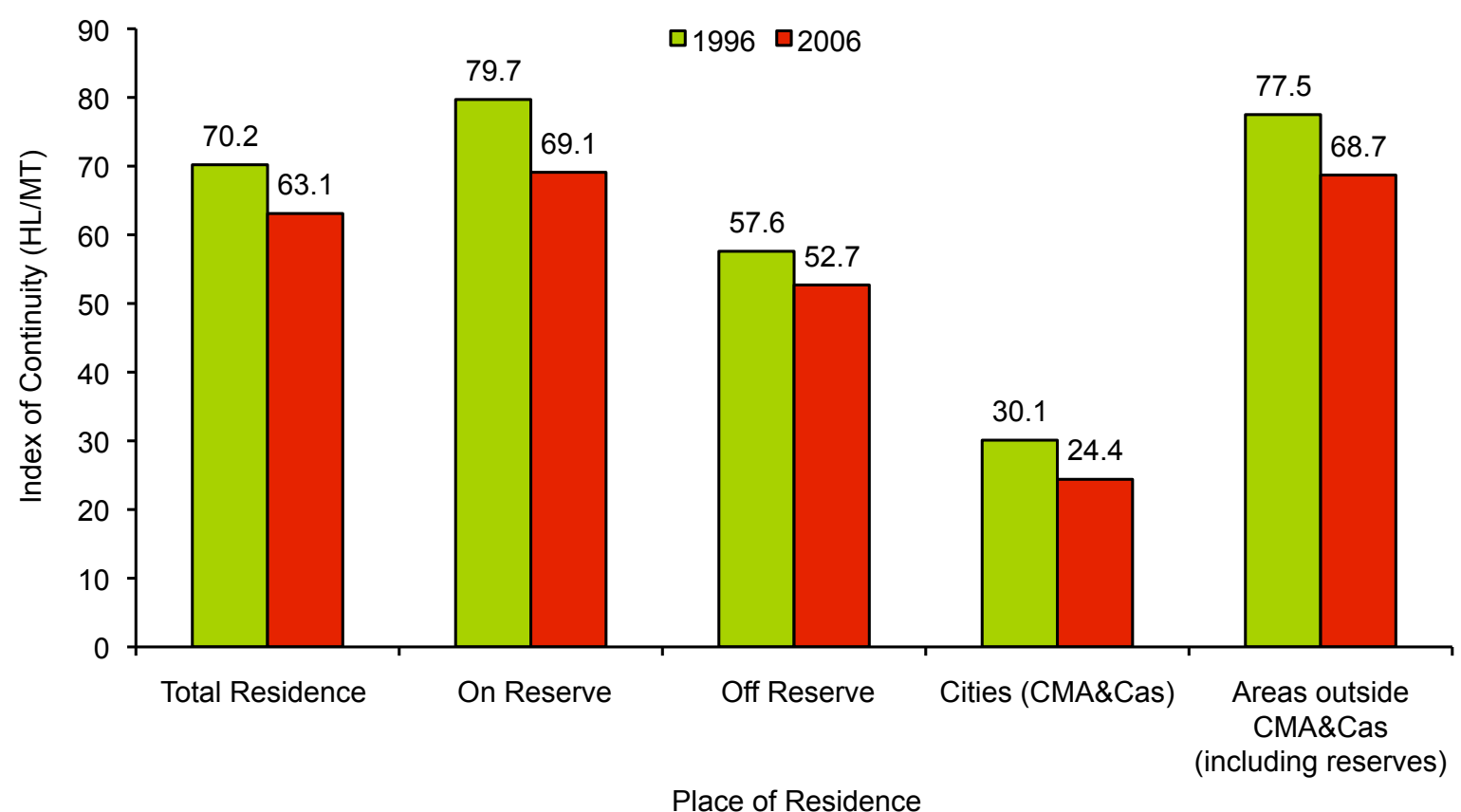

Source: 1996 and 2006 Census of Canada (unadjusted data)

Figure 8: Index of Aboriginal Second Language Acquisition (SLA), by

On/Off Reserve and Within/Outside City (CMA\&CAs) Places of

Residence, Canada, 1996 and 2006

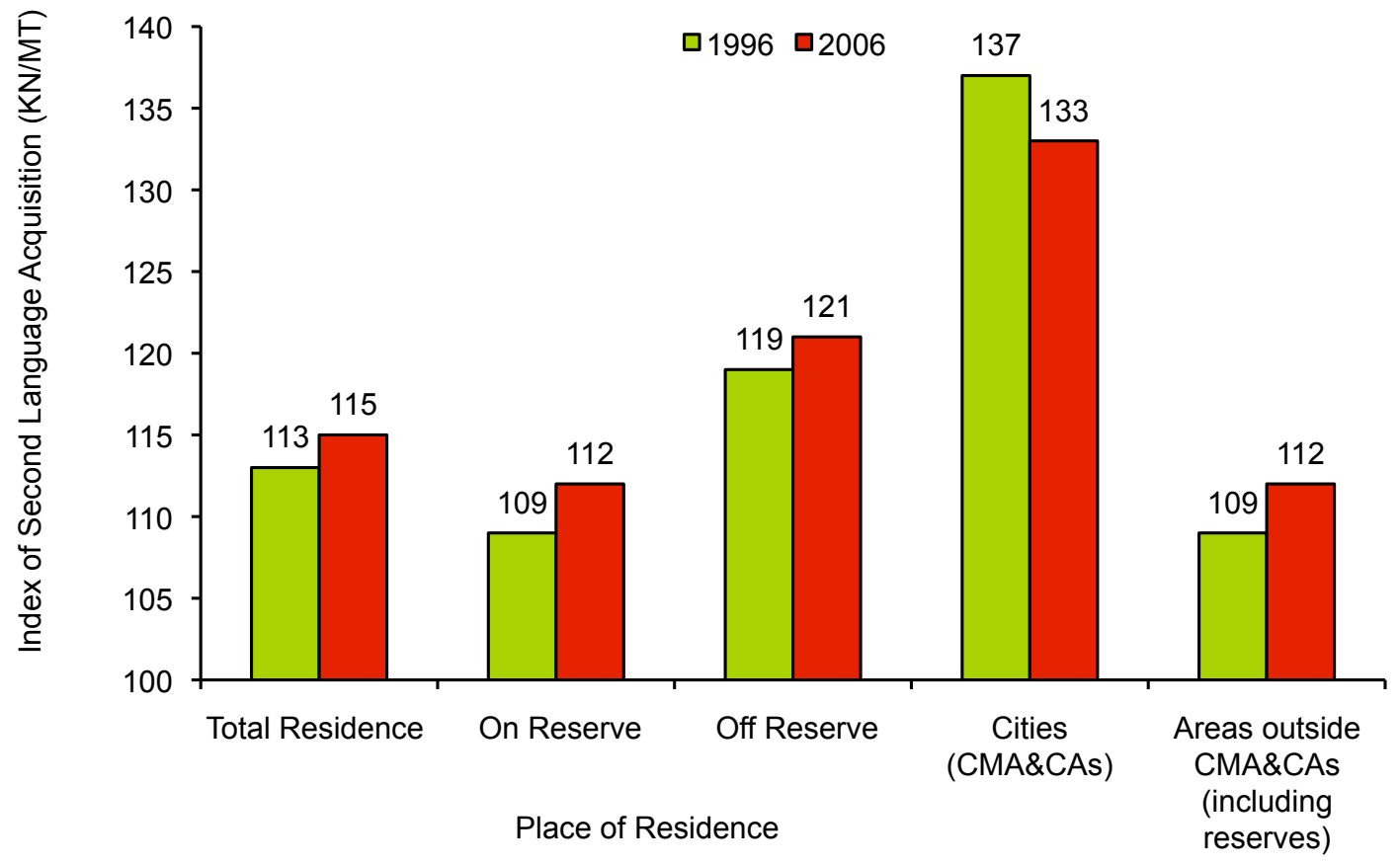

Source: 2006 Census of Canada (unadjusted data) 
suggests significant challenges of language maintenance within the urban environment, and serious implications for intergenerational transmission within urban areas (Norris 1998, 2003, 2009). It would imply that urban Aboriginal youth are more likely than their counterparts outside cities to learn their traditional language as a second language.

\section{In Cities, Second Language Speakers Much Younger than Mother Tongue (First Language) Speakers}

As a consequence of residential patterns of home language use, not only are populations with an Aboriginal mother tongue older than the Aboriginal population in general (with an average age of 29 in 2006), they are significantly older in areas outside reserves. This is especially the case in urban areas, and most notably in the large census metropolitan areas (CMAs) where the average age of the mother tongue population was 42 years in 2006. This is in sharp contrast to the average ages of 33 and 31 years among residents on reserves and in rural areas, respectively. Given that youth are also more likely than older generations to learn their Aboriginal language as a second language, especially in urban areas, the average ages of populations with the ability to speak an Aboriginal language that include second language speakers also tend to be younger than their corresponding mother tongue populations. For example, within large cities (CMAs) in 2006, the average age of the population reporting the ability to speak an Aboriginal language, at 39 years, was three years younger than the population with an Aboriginal mother tongue. In reserve and rural areas where second language learning is less pronounced, the average ages of mother tongue and all speakers were closer, with only a one year difference on reserves. There was practically no difference in average ages in rural areas, where the average age of the population with an Aboriginal mother tongue and ability to speak the language was the same at 31 years, and also the youngest, probably a reflection in part of the effect of the younger Inuit speakers and their rural communities in the rural category (Figure 9).

\section{In Cities, Older Speaker Populations with Lower Shares of Children and Youth}

Speakers of Aboriginal languages who are residing in cities are older, on average, with higher ages when compared to speakers overall, and to those 
Figure 9: Average Age of Aboriginal Population with Aboriginal Mother Tongue or Knowledge of (Ability to Speak) an Aboriginal Language, Canada, 2006

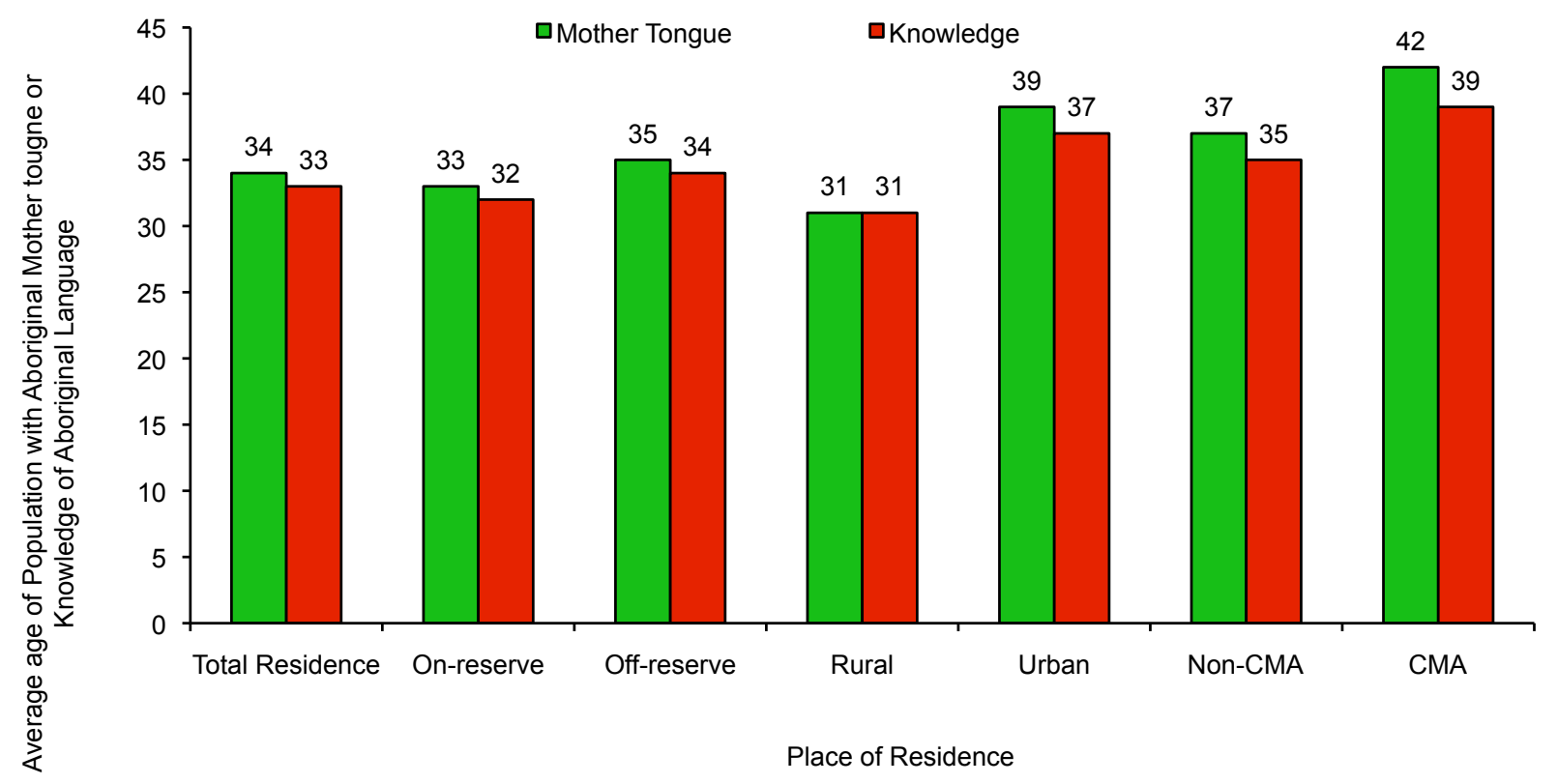

Source: 2006 Census of Canada (unadjusted data)

living on reserves and in Aboriginal communities. Consistent with these age differences, children and youth in urban areas make up much lower shares of the population with an Aboriginal mother tongue or the ability to speak an Aboriginal language than in rural and reserve areas outside cities, especially in large cities (urban CMAs) (Norris 2003, 2007, 2008, 2009; Norris and Snider 2008). In general, Aboriginal children and youth are more likely than older generations of speakers to learn their traditional language as a second language. As a consequence, they account for a higher share of the population able to speak an Aboriginal language (including second language speakers), than that of the mother tongue (first language) population.

According to the 2006 Census, children (ages 0-14) and youth (ages 15-24) together make up 45 percent (27\% and 18\% respectively) of the Aboriginal population living within urban CMAs, yet account for a disproportionately low share of the Aboriginal CMA population reporting an Aboriginal mother tongue, at only 19 percent. While the share of children and youth in the CMA population able to speak an Aboriginal language is also low, it is nevertheless at 25 percent, higher than that of the CMA 
Aboriginal mother tongue population (19\%). On reserves, where children and youth account for just over half (52\%) of the Aboriginal population, they represent 41 percent and 42 percent respectively of the population with an Aboriginal mother tongue or ability to speak an Aboriginal language (Figure 10). Children and youth make up the largest share of mother tongue and total speaker populations in rural areas, at 45 percent and 44 percent, respectively, followed by reserves, urban non-CMAs areas at 31 percent and 35 percent, and the smallest share of these populations being in urban CMAs (Figure 11).

The relatively low shares of children among Aboriginal mother tongue and speaker populations in urban areas, as well as the size of speaker populations particularly for CMA and CA cities (including reserves within their boundaries), have remained remarkably unchanged between 1996 and 2006. The populations reporting an Aboriginal mother tongue in CMAs and CAs (including reserves) were about the same, at some 40,000 in 1996 and 42,000 in 2006, as well as for the population with knowledge of or ability to speak an Aboriginal language at about 53,000 for both 1996 and 2006 (Table 2a). It appears that children and youth living in these areas have consistently, over the decade in question, accounted for about one in four persons reporting an Aboriginal mother tongue (26\% in 1996, and $27 \%$ in 2006), and for somewhat higher proportions of persons able to speak an Aboriginal language, at 30 percent in 1996 and 31 percent in 2006 (Figure 12).

Figure 10: Age Composition of Aboriginal Population Residing on Reserves and in Large Cities (CMAs) with an Aboriginal Mother Tongue or Language Knowledge, Canada, 2006

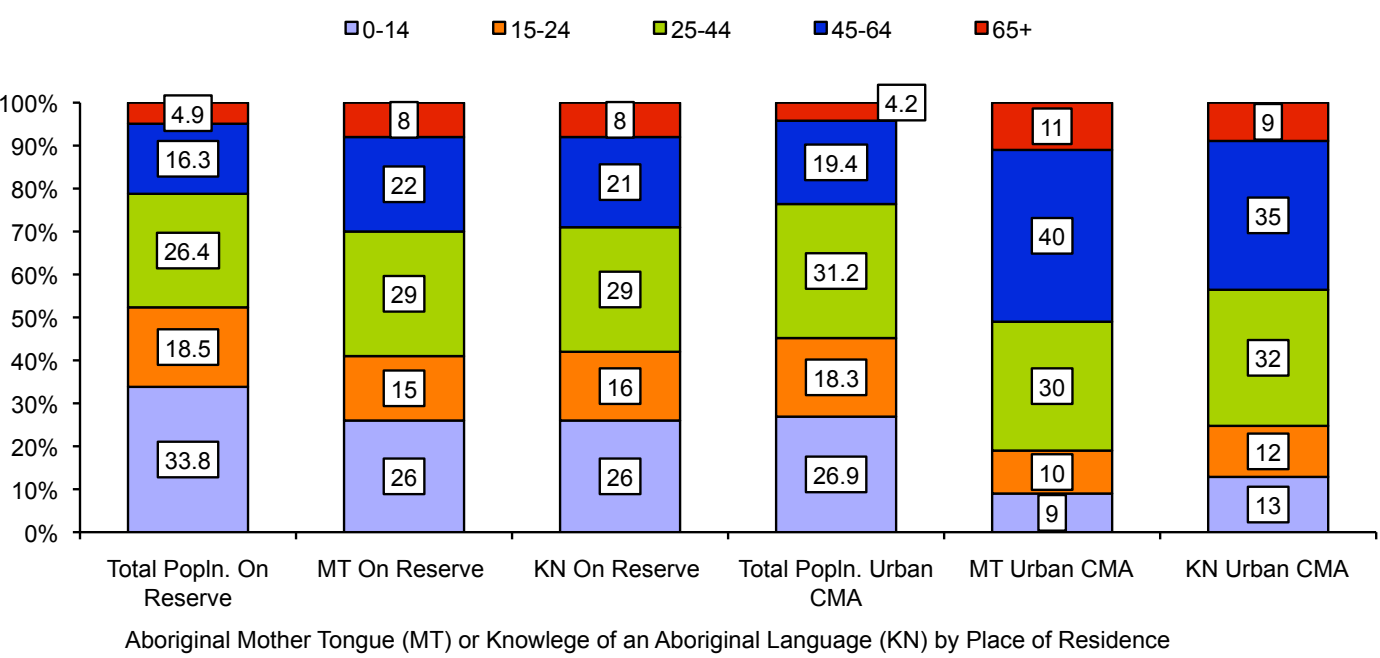

Source: 2006 Census of Canada (unadjusted data) 
Figure 11: Age Composition of Aboriginal Populations with an Aboriginal Mother Tongue or Language Knowledge by Place of Residence, Canada, 2006

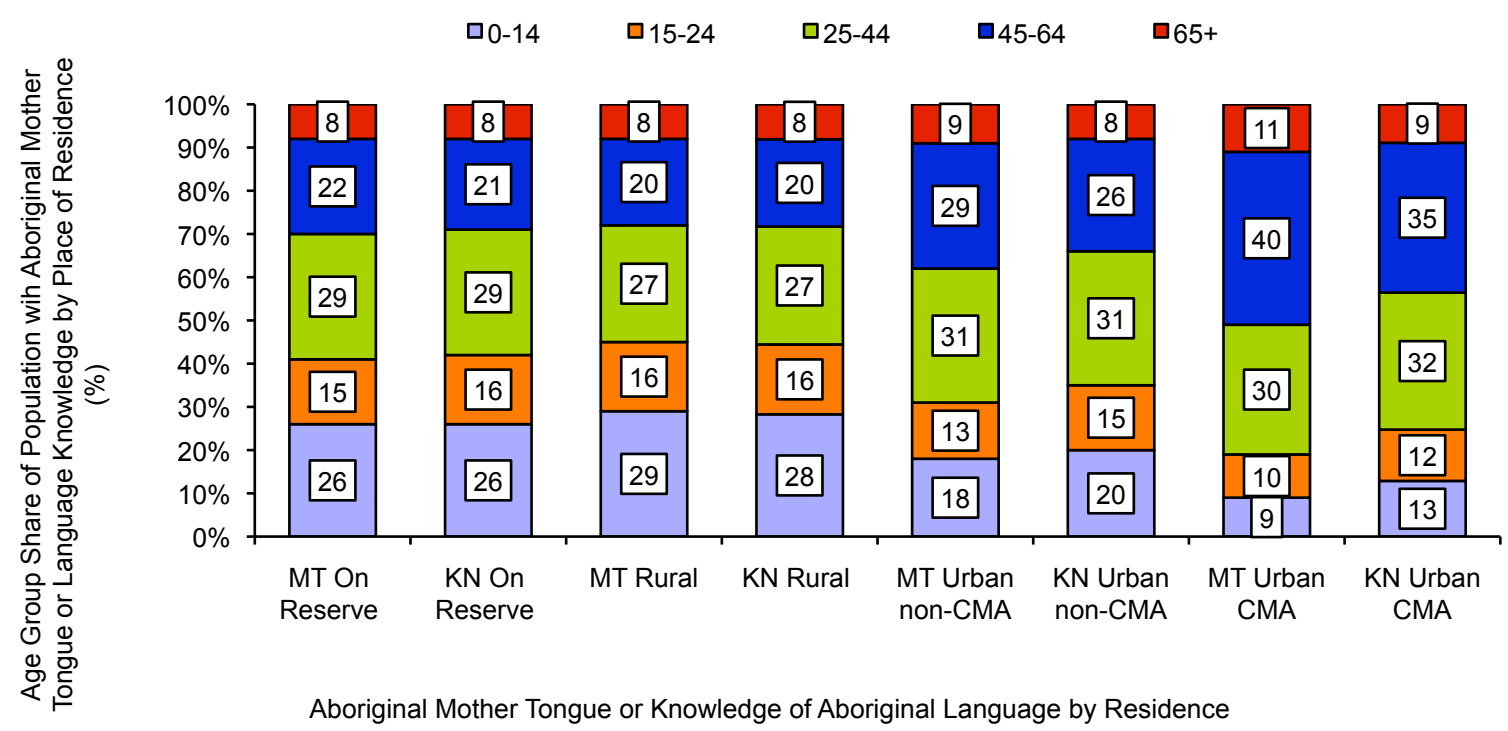

Source: 2006 Census of Canada (unadjusted data)

Figure 12: Age Composition of Aboriginal Populations in Cities (CMAs \& CAs) with an Aboriginal Mother Tongue or Language Knowledge by Broad Age Groups, Canada, 1996, 2006

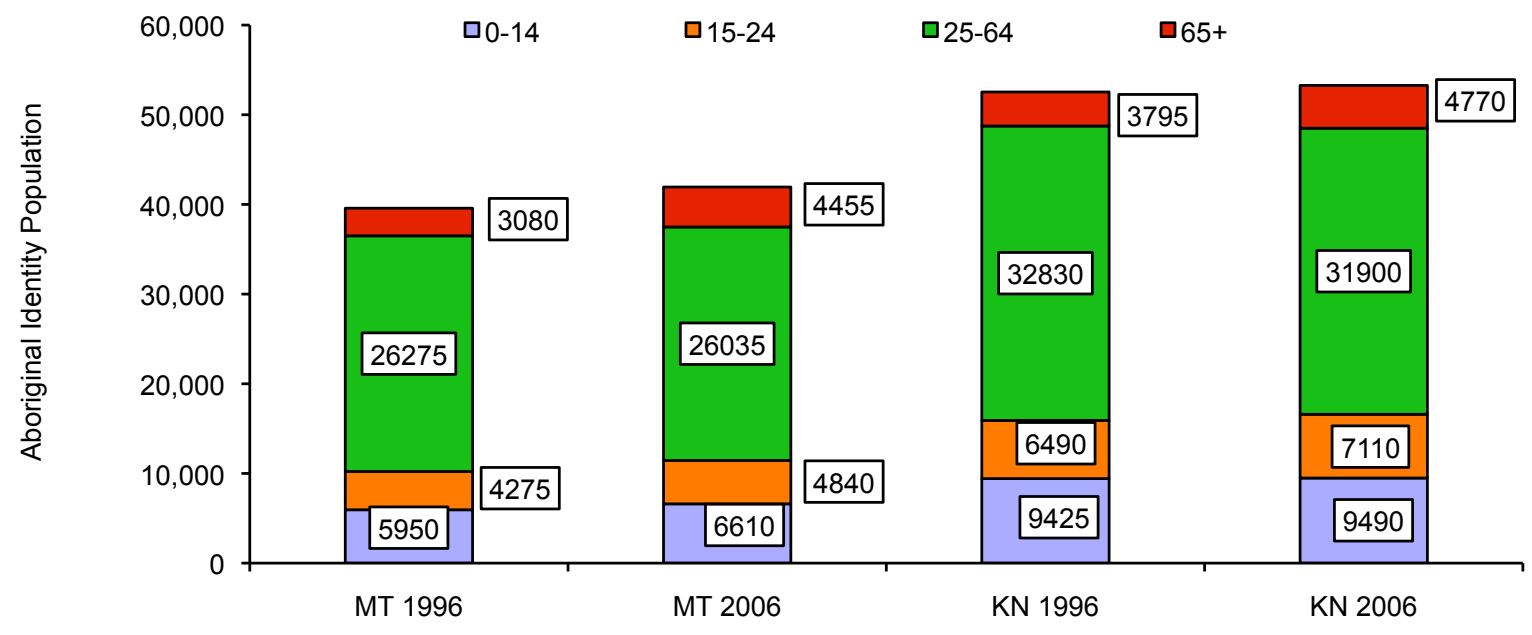

Aboriginal Mother Tongue or Knowledge of an Aboriginal Language

Source: 1996 and 2006 Census of Canada (unadjusted data) 


\section{Youth in Cities: Patterns in Home Use; First and Second Language Composition of Speakers Consistent over Past Decade}

Age-specific language patterns in home use, learning, and the first and second language composition of speakers have remained fairly similar over the past decade. When comparing across age groups over time, it is important to remember that we are seeing the outcomes of different cohorts. As well, when assessing changes in language characteristics between censuses by residence, we are not necessarily comparing the same populations but, rather, different populations that have been shaped by the compositional effects of migration, natural increase, and population growth, as well as by patterns of language acquisition and learning. Comparisons of the language characteristics of Aboriginal populations in cities between 1996 and 2006 suggest three consistent age-related patterns. First, there is a clear pattern of proportions of urban residents reporting an Aboriginal mother tongue or ability to speak an Aboriginal language rising with increasingly older generations: in 2006, for example, just over 4 percent of young adults (15$24)$ in cities reported an Aboriginal mother tongue as compared to 16 percent of people aged 65 and over residing in cities (CMAs and CAs combined, including reserves within boundaries). A second consistent pattern observed over the decade across all generations is the higher proportion of the population able to speak an Aboriginal language when compared to proportions with an Aboriginal mother tongue, with differentials being more pronounced among younger age groups. In contrast, a third pattern holding steady over the decade is associated with the notably lower proportions speaking an Aboriginal language most often at home compared to the mother tongue shares. Differences were more pronounced among adults, especially in the $65+$ age group, than among children and youth, where proportions with an Aboriginal mother tongue are also much lower and more similar to major home language use (Figures 13 and 14).

Corresponding to these patterns, the index of second language acquisition suggests higher ratios among younger generations of second language learners to mother tongue populations, which could imply that Aboriginal youth are more likely than older adults to have learned their Aboriginal language as a second language, as is the situation at the Canada level, regardless of residence (Norris, 2007). Within cities in 2006, 147 youth (aged 15-24) were able to speak an Aboriginal language for every 100 youth with an Aboriginal mother tongue, indicating that 47 must have 
Figure 13: Second Language Index and Proportions of Aboriginal Populations in Cities (CMAs \& CAs) (including reserves within city boundaries) reporting an Aboriginal Mother Tongue / Language Knowledge, by Broad Age Groups, Canada, 1996, 2006

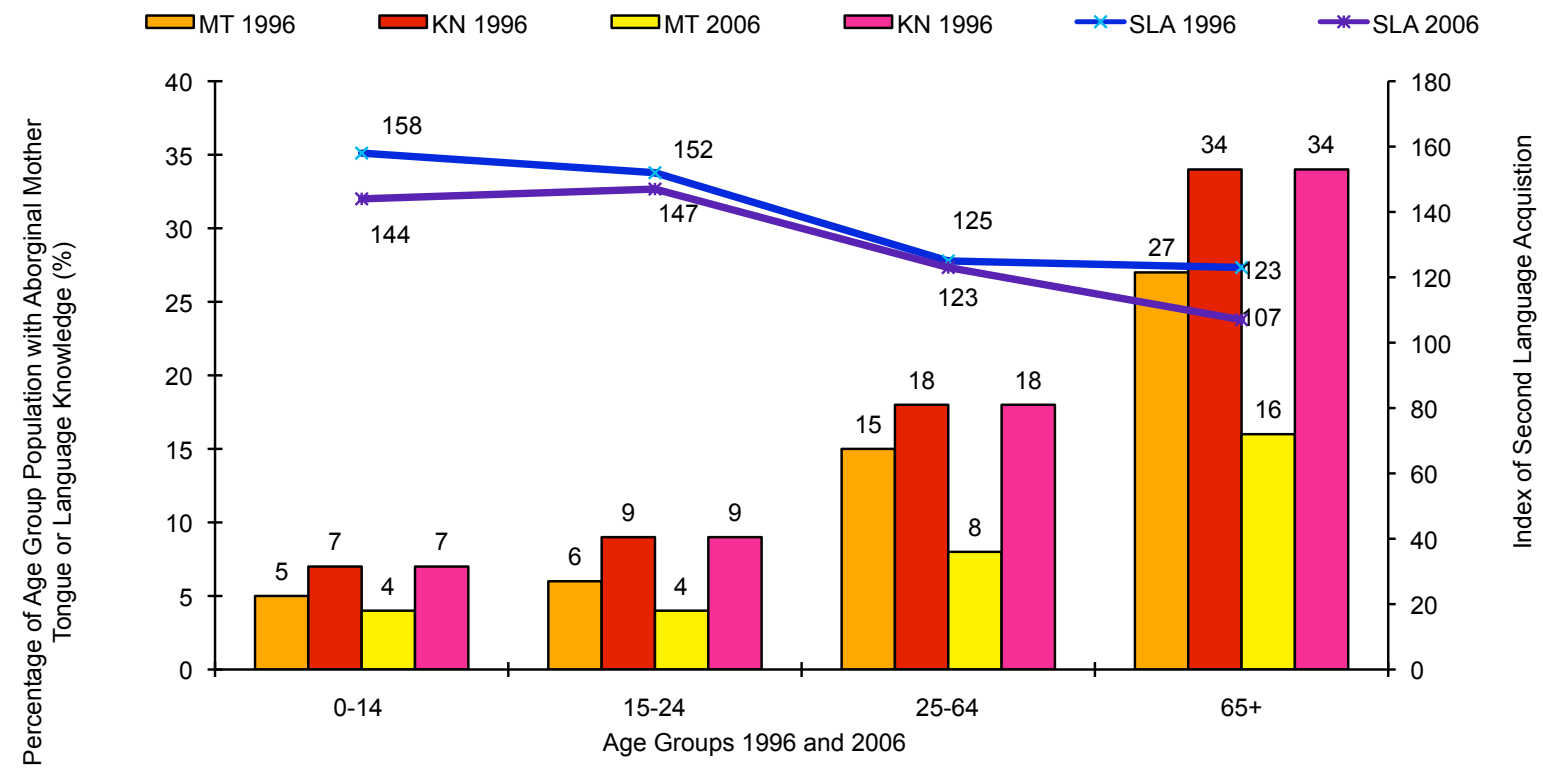

Source: 1996 and 2006 Census of Canada (unadjusted data)

Figure 14: Index of Language Continuity and Proportion of Aboriginal Populations in Cities (CMAs \& CAs) (including reserves within city boundaries) reporting an Aboriginal Mother Tongue / Home Language by Broad Age Groups, Canada, 1996 and 2006

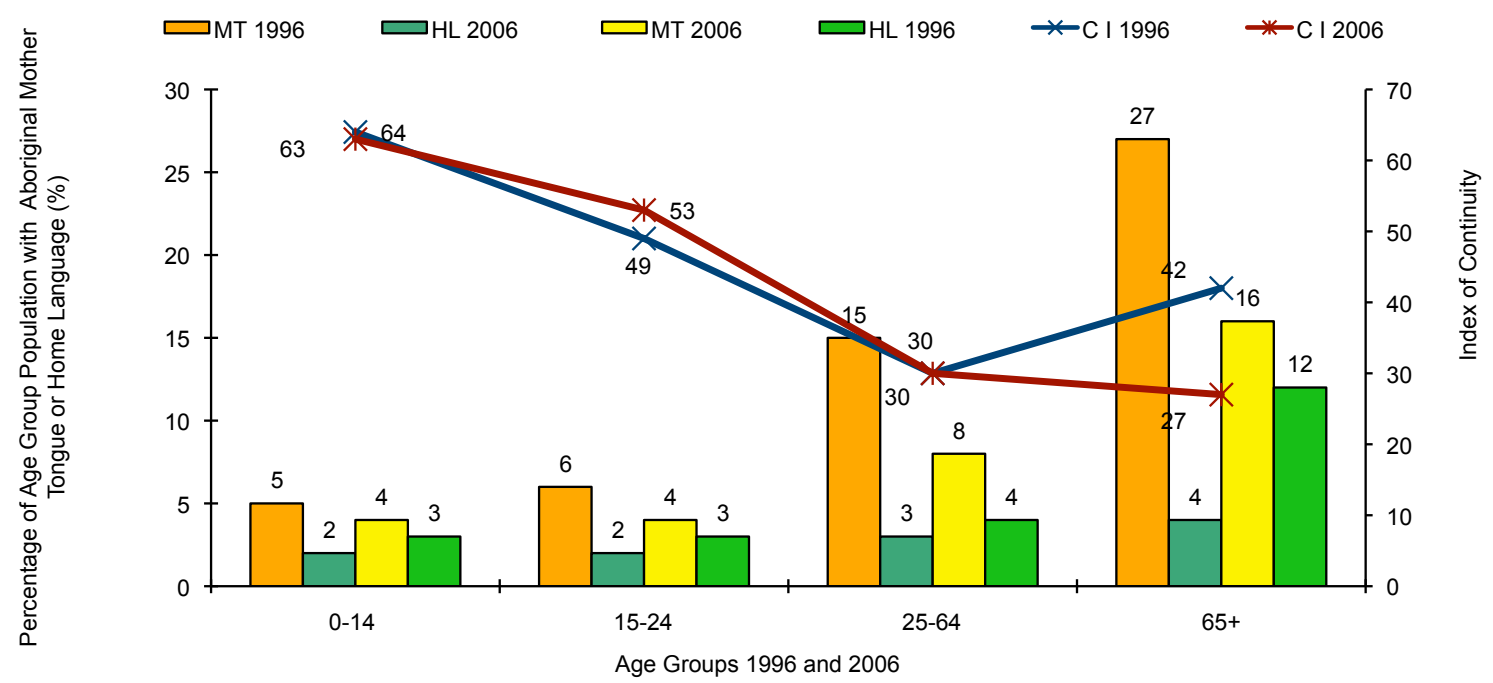

Source: 1996 and 2006 Census of Canada (unadjusted data) 
learned their language as a second language. Whereas, for older adults 65 years of age and over, there were 107 speakers for every 100 with an Aboriginal mother tongue. As well, the index of continuity, which is low in cities overall, indicates that major home language use is notably lower among adults of working age on, as compared to youth and children who, if they have acquired an Aboriginal mother tongue, are more likely to still be learning and using it at home than working age adults with an Aboriginal mother tongue (Figures 13 and 14).

Between 1996 and 2006, Aboriginal Populations in Cities See Decrease in Proportions of Speakers; Continued Low Language Continuity and High Ratio of Second Language Speakers Across All Ages

While age-related patterns have remained the same over the decade, the proportions of speakers (both mother tongue, and first and second language speakers combined) declined, a reflection in part of the impact of high Aboriginal population growth in cities between 1996 and 2006. Declines at older ages, such as the proportion of the population aged $65+$ with an Aboriginal mother tongue from 27 percent in 1996 to 16 percent by 2006, are also effects of younger cohorts with lower proportions of speakers aging into older age groups over the decade, and of compositional effects noted earlier. Finally, both the indexes of continuity and second language acquisition appeared to have lessened slightly over the decade, but generally remained relatively stable across most age groups. In the case of the 65+ age group, though, the continuity index saw a decrease from 42 in 1996 to 27 in 2006; again, perhaps reflecting effects of younger cohorts with lower home language use in 1996 ageing into the older, 65+ groups of 2006 (Figures 13 and 14).

\section{Youth in Cities: Age and Residential-Related Patterns of Language Acquisition and Use, 2006}

In terms of both age and residential-related patterns of language learning and home use among Aboriginal children and youth in 2006, those living in large cities (urban CMAs) experienced the lowest levels of language continuity, of major home use with continuity indexes of 50 and 35, respectively. Use of an Aboriginal language as the primary home language was highest among children and youth living in rural areas (with corresponding indexes of 84 
and 82 respectively), and on reserves, with indexes of 78 and 75 (Figure 15). In terms of language learning, Aboriginal children and youth appear most likely to be second language learners if they reside in large cities (urban CMAs), with second language indexes of 174 and 160 respectively, and seem least likely to have learned their traditional language as a second language if they live in rural or reserve areas, with similar indices of 112 and 115 respectively (Figure 16).

\section{Aboriginal Languages in Cities Spoken at Home on a "Most Often" or "Regular" Basis, 2006}

As noted in the previous section on residential language patterns, the propensity to speak an Aboriginal language in urban homes, whether on a "most often" or "regular" basis, is low, with only 1 percent and 2 percent respectively of Aboriginal populations in cities (CMAs and CAs, excluding reserves) compared to areas outside of cities, where 29 percent and 7

Figure 15: Index of Aboriginal Language Continuity by Age Groups by Place of Residence, Canada, 2006

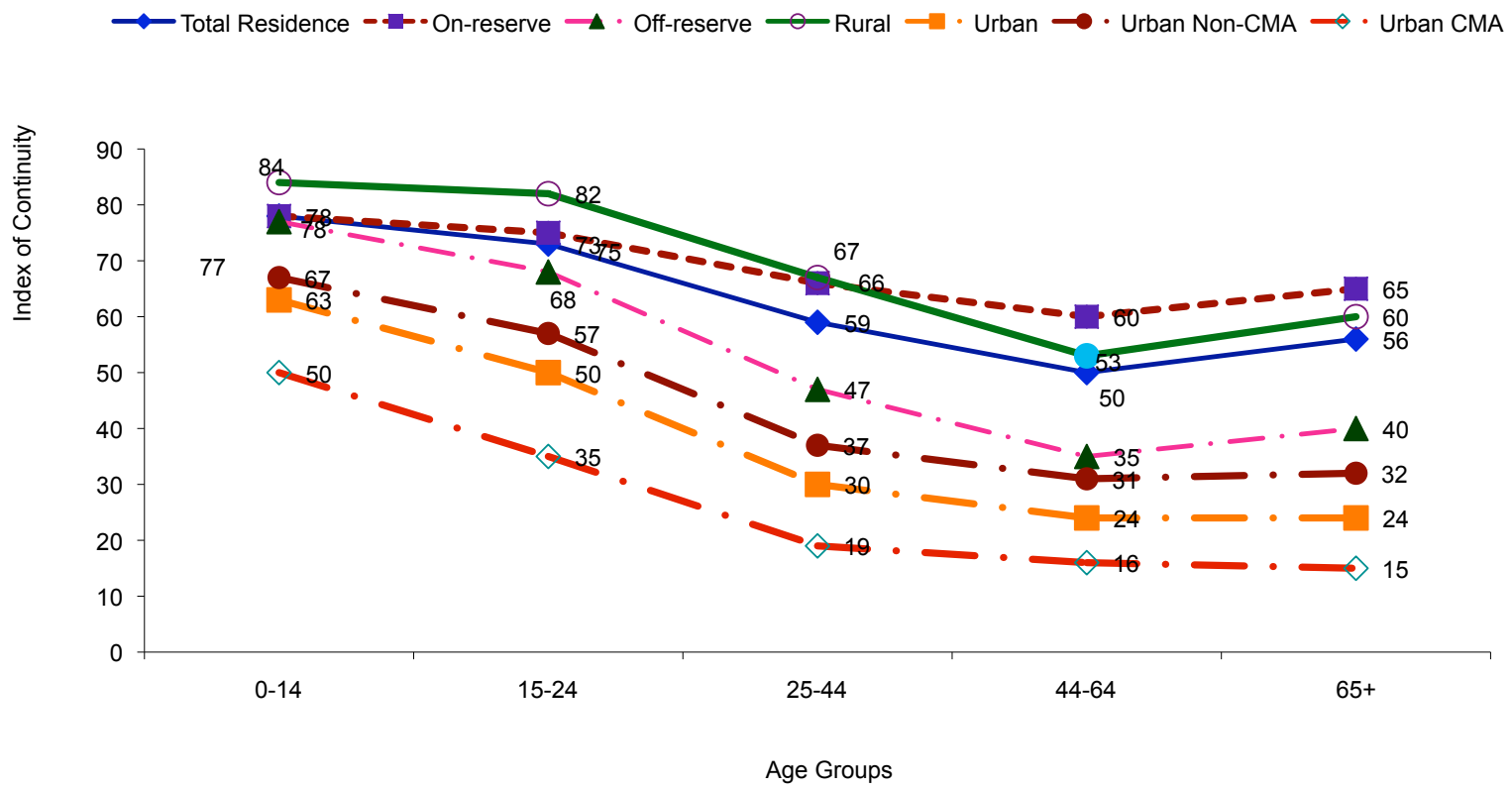

Source: 2006 Census of Canada (unadjusted data) 
Figure 16: Index of Aboriginal Second Language Acquisition (SLA), by Age Group, by Place of Residence, Canada, 2006

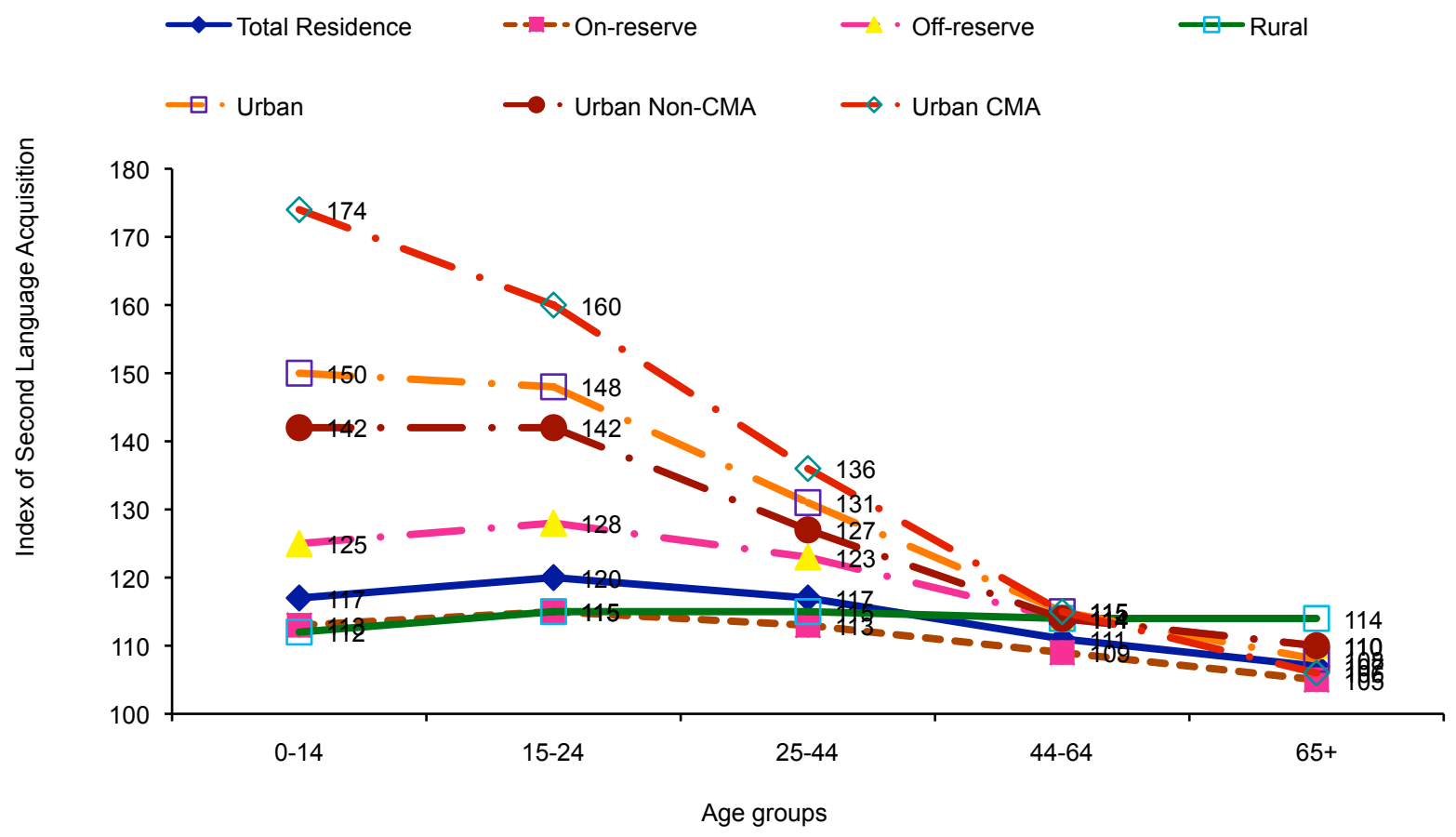

Source: 2006 Census of Canada (unadjusted data)

percent speak their Aboriginal languages on a "most often" or "regular" basis respectively. And, clearly the impact of where one lives on the use and frequency of speaking an Aboriginal home language significantly affects all ages, young and old. In 2006, practically half (49\%) of older Aboriginal adults aged 65+ residing on reserves spoke an Aboriginal language as their primary home language, while another 14 percent spoke it on a regular basis . Yet, among their counterparts living outside reserves and communities and especially in large cities (urban CMAs), home use plummets, with only 2 percent and 3 percent of the $65+$ population reporting frequent or regular use respectively of an Aboriginal home language. Hardly any of the Aboriginal youth (aged 15 to 24) living in large cities spoke an Aboriginal language at home, on either a "most often" (1 percent) or "regular" (1\%) basis. The impact of cities on home use of Aboriginal languages is significant for youth, as well as older adults, considering that, on-reserve, about 28 percent of youth speak their traditional languages as major home languages, while another $7 \%$ speak them regularly at home (Figures $17 \mathrm{a}$ and $17 \mathrm{~b}$ ). 
Fig 17a: Average Age and Percentage of Identity Population Speaking an Aboriginal Language on a "Most Often" basis at Home

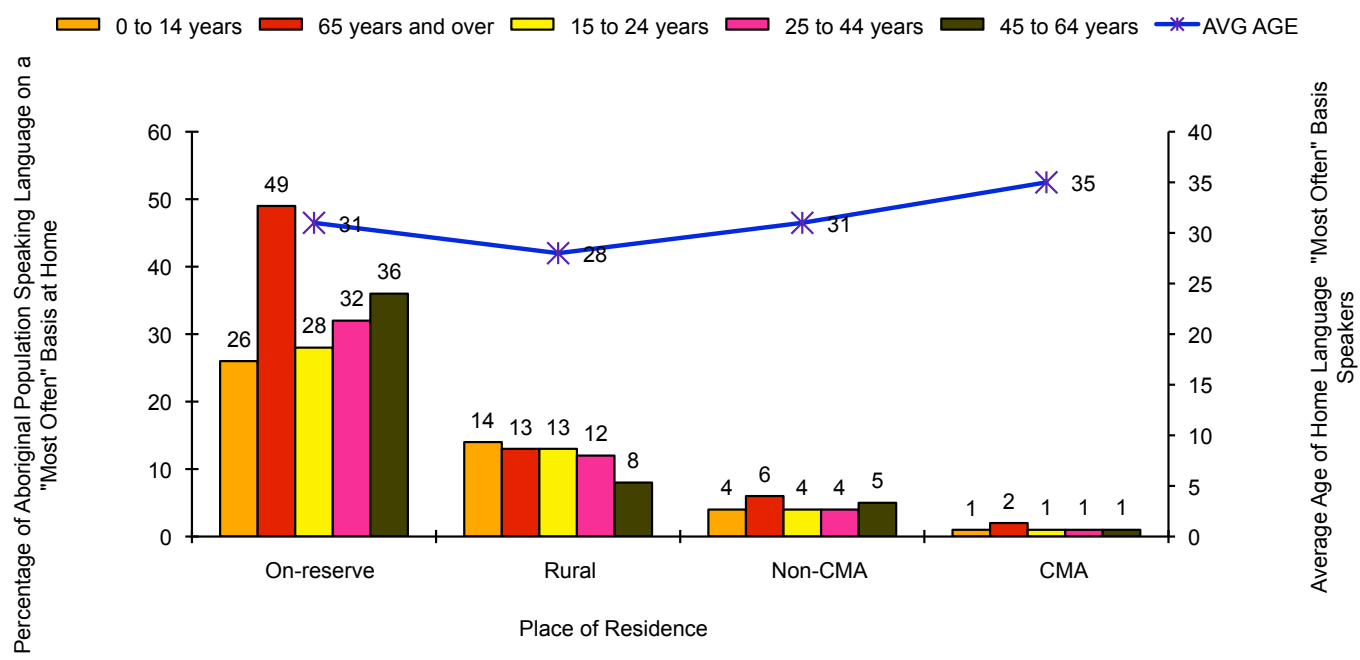

Source: 2006 Census of Canada (unadjusted data)

Figure 17b: Average Age and Percentage of Identity Population Speaking an Aboriginal Language on a "Regular" basis at Home

ש 0 to 14 years 65 years and over 15 to 24 years 25 to 44 years 45 to 64 years $\rightarrow$ AVG AGE

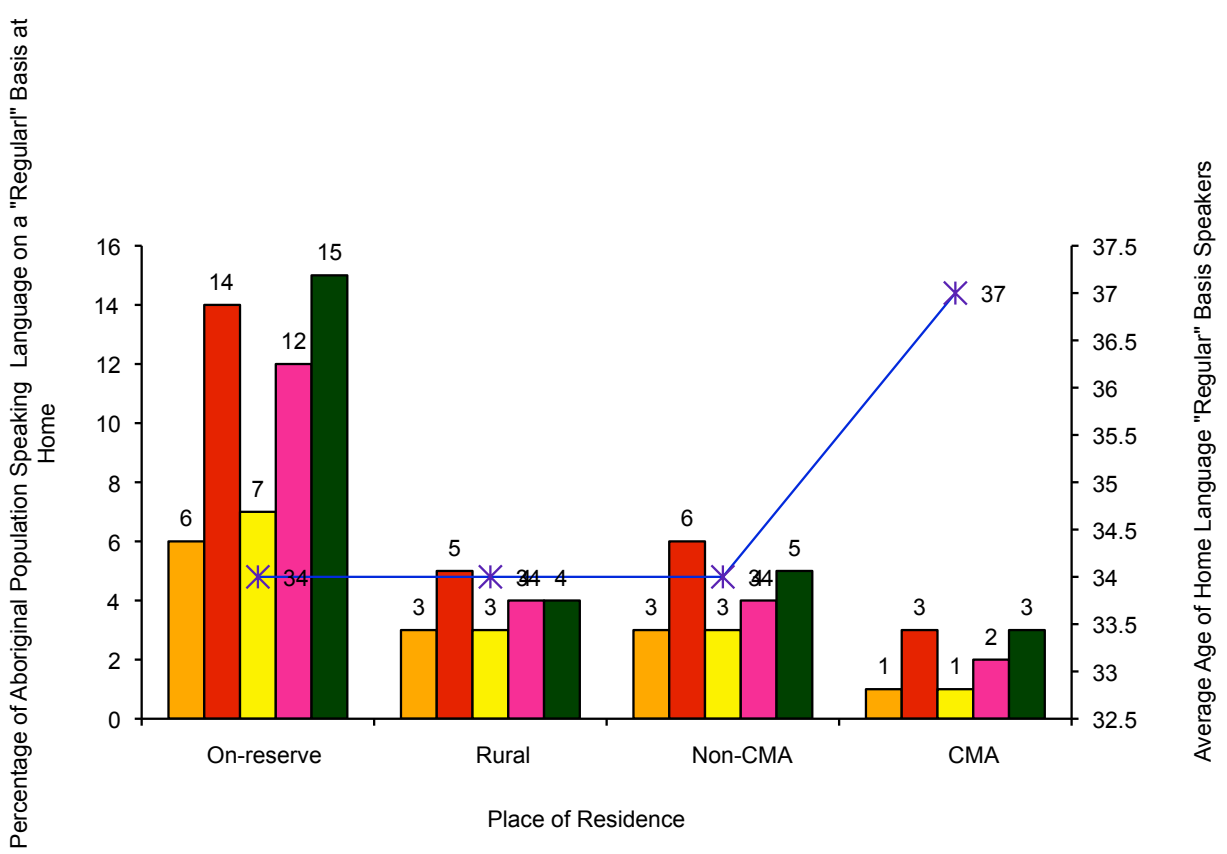

Source: 2006 Census of Canada (unadjusted data) 
The outcomes of these age patterns of home language use by place of residence are reflected in the average ages of home language speakers. For example, the average age of persons on reserves speaking an Aboriginal language as their major home language is 31 years, as compared to an older population of home users in large cities, with an average age of 35. Similarly, the population of regular home language speakers tends to be younger on reserves, with an average age of 34 years, compared to an average age of 37 in large cities. As well, regardless of residence, home language speakers who speak their Aboriginal language on a "regular" basis tend to be older on average than those speaking it on a "most often" basis. Although it is not immediately clear why this may be so, it could reflect the effect of older cohorts who, more likely than younger generations to be first language speakers, may also be more likely to continue speaking at home even if on a regular basis than younger generations, as appears to be the case for residents both on reserves and in large cities (Figures 17a and 17b).

\section{At All Ages, Home Language Users in Cities Are Considerably More Likely, to Speak Their Aboriginal Languages on a "Regular," Rather Than a "Most Often," Basis}

As noted earlier, Aboriginal residents in cities are much more likely to speak their traditional languages on a regular basis, rather than on a most often basis. This is especially so in large cities - a pattern which contrasts most sharply with that on reserves. In 2006, in large cities, practically two out of three people (65\%) speaking an Aboriginal language at home spoke it on a regular basis, compared to just one in four (24\%) of home language speakers on reserves. And, this contract between city and reserve occurs across all ages. In the case of children and youth (aged 0 to 24) who use an Aboriginal language at home, the majority (60 percent) among those living in cities speak their traditional language not as a major language but, rather, on a "regular" basis at home. The situation is practically the opposite for children and youth on reserves, where the vast majority, about 80 percent, speaks their traditional language as the major language, such that only 20 percent are "regular-use" speakers. It is not surprising then that children living on reserves are much more likely than children in cities to acquire their Aboriginal language as a mother tongue. Both on reserves and in cities, working-age adults (25 to 64 years) are to some extent more likely than younger generations and older adults (aged 65+) to be speaking 
their language on a regular basis. For example, in large cities, close to 70 percent of working-age residents speaking an Aboriginal language in the home spoke it on a regular basis, compared to about 60 percent of children and 62 percent of older adults. To some extent, children and youth, if speaking a language at home are likely to be using it within the family context of parent-child transmission, and hence, with young parents, may be somewhat more likely than older working-age adults to be speaking it as the major home language (Figure 17c).

\section{Implications and Conclusions}

Findings demonstrate the significant presence of Indigenous languages within urban Canada's major city areas. The past decade has seen a continuation of the same patterns of similarities and differences in the language situations of Aboriginal peoples, between those residing in cities and those living in Aboriginal communities and locations outside of cities. Prospects of learning, using, and speaking an Aboriginal language vary

Figure 17c: Distribution of Home Language Users Speaking their Aboriginal Language by Degree of Use - On a "Most Often" or "Regular" Basis at Home, by Age Groups, On Reserves and in Large Cities (CMAs), Canada, 2006

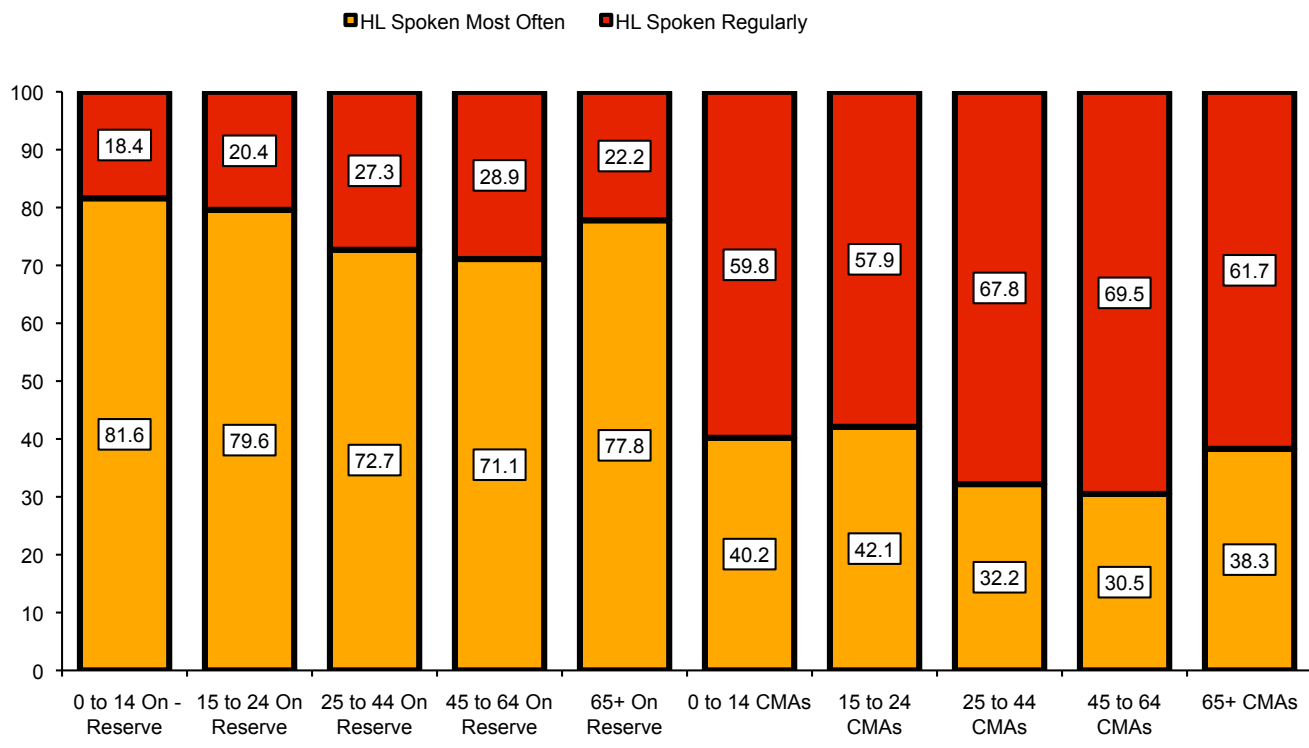

Age Groups of Aboriginal Residents residing on Reserve and in Large Cities (CMAs) 
significantly by place of residence for all Aboriginal groups, including First Nations, Métis, and Inuit. Aboriginal people residing in urban areas remain much less likely to report an Aboriginal language as a mother tongue or as a major home language than those living in Aboriginal communities or on reserves. In terms of language acquisition, Aboriginal people who can speak their traditional language appear more likely to have learned it as a second language if they live in urban areas, than in Aboriginal and reserve communities and locations outside of city areas. In urban areas, prospects of intergenerational transmission of an Aboriginal mother tongue are poor, as evidenced by extremely low use of traditional languages as a primary language in urban homes. Aboriginal children and youth in urban areas therefore continue to remain much less likely than those in rural areas, communities and reserves outside of cities to acquire an Aboriginal language as a mother tongue.

Urban and non-urban areas do share some similarities in age characteristics of first and second language speakers of Aboriginal languages. Regardless of residence, on-reserve or off-reserve, in rural locations, or in urban areas small or large, the younger average age of all speakers who can conduct a conversation in an Aboriginal language points to second language speakers being younger on average than first language speakers. These age contrasts appear most pronounced in large city areas (urban CMAs) where second language speakers would appear to be much younger than the mother tongue population. However, in urban areas, especially in large cities, Aboriginal people who can speak their traditional language, whether as a first or second language, are, on average, significantly older than their counterparts residing in Aboriginal communities on reserves or in rural areas.

Although the past decade has yielded a continuation of certain patterns and contrasts in language states, results also point to a widening of urban-non-urban differentials. Between 1996 and 2006, the population with an Aboriginal mother tongue or ability to speak an Aboriginal language increased outside of cities, but decreased within cities. While the decade has seen a shift in the residential distribution of the Aboriginal identity population towards urban areas, the distribution of Aboriginal language speakers has seen a shift away from cities towards rural areas, and Aboriginal and reserve communities. When compared to 1996, the population of Aboriginal language speakers living in cities in 1996, those in 2006 (although not directly comparable for reasons noted earlier), while 
similar in number, appear to be somewhat lower and older on average, for both first language and all (including second language) speakers.

Findings from 2006 also attest to the challenges in cities of speaking an Aboriginal language as the major language of the home. Among city residents who spoke an Aboriginal language at home, the majority used their traditional language on a "regular" but not "most often" basis, in sharp contrast to Aboriginal communities, where most home-language speakers speak their traditional language as the major language of the home.

This study suggests that, ten years later, urban Aboriginal people continue to experience significant challenges and issues in the maintenance and revitalization of their traditional languages within the city environment. However, findings also have implications for possible strategies, in addressing those urban challenges for Aboriginal languages.

\section{Challenges and strategies for language maintenance and revitalization in urban areas and cities}

The challenges of "being surrounded by non-Aboriginal people and cultures" and of "heterogeneity" identified in "the emergence and maintenance of positive urban Aboriginal identities" (Peters 2011, 85) are also clearly at play for Aboriginal languages in urban areas and cities. As noted, there is a significant diversity of Aboriginal languages, with about ninety different languages spoken in various regions across Canada, including some in urban areas as well as in Aboriginal communities and locations outside cities. The effect of the larger mainstream languages of English or French in daily life are evident in the patterns of Aboriginal language use in urban homes, where they are rarely spoken as a major language, and where prospects of intergenerational transmission of a mother tongue are consequently low.

Major home use and transmission as a mother tongue or first language, which ideally yield the best prospects for Aboriginal languages, tend to be difficult within a city environment. However there are also signs that urban Aboriginal residents are finding other strategies for speaking and learning their traditional languages, in ways that are perhaps more feasible within urban environments - not in use as major home languages and not in transmission as mother tongues but, instead, speaking their languages at least on a regular basis within the home, and learning their languages as second languages. Thus, in urban environments, second language learning and regular home use of Aboriginal languages become 
increasingly important components of language survival, maintenance, and revitalization, especially among younger generations.

Patterns and trends of urban Aboriginal language use and learning suggest important avenues and approaches for language planning, programs, and policies, ones that may be more attainable; and, perhaps in the long run, if recognized and supported, could contribute to urban environments that may be more conducive to sustaining and establishing the presence of traditional languages, and cultures, within the daily lives of Aboriginal people living in Canada's cities.

Research demonstrates that Aboriginal languages can play a significant role in the lives of Aboriginal people in many areas, such as their culture, identity and well-being; health and education; and in family and communications across generations. Trends in urbanization, plus the significance of traditional languages for Aboriginal peoples, reinforce the importance of the maintenance and revitalization of Aboriginal languages, especially for children and youth, for those living within urban areas and major cities across Canada.

\section{Endnotes}

1. This article represents an update of the essay "Aboriginal languages in Canada's Urban Areas: Characteristics, Considerations and Implications" (Norris and Jantzen 2003).

2. This article is based on an earlier version of a paper prepared by the author for the Department of Canadian Heritage's Strategic Policy and Management Branch. The views expressed in this paper are those of the author and do not necessarily represent the views of the Department of Canadian Heritage. The author would like to acknowledge, with thanks, the management and support of this project provided by Lorna Jantzen and Mike Musca.

3. For a discussion on the impact of the Indian Act and its 1985 provisions (Bill C-31) on Aboriginal languages, see Norris 2009.

4. The term "cities" is used interchangeably with Census Metropolitan Area (CMAs) and Census Agglomerations (CAs). A CMA is a very large urban area, including urban and rural fringes and reserves, with an urban core 
population of at least 100,000. A CA is a large urban area, including urban and rural fringes and reserves, with an urban core population of at least 10,000 . In this analysis, the presence of reserves is controlled for such that reserves in urban areas are generally excluded.

\section{References}

Abley, Mark. 2003. Spoken Here: Travels Among Threatened Languages. Toronto: Vintage Canada.

Ball, Jessica. 2009. "Aboriginal young children's language development: Promising practices and needs." Canadian Issues / Thèmes canadiens (CITC) (Winter 2009): 37-44.

Belanger, Yale, Liz Barron, Charlene McKay-Turnbull, Melanie Mills. 2003. Urban Aboriginal Youth in Winnipeg: Culture and Identity Formation in Cities. Report prepared for Canadian Heritage, Winnipeg, MB.

Bougie, E. 2010. "Family, community, and Aboriginal language among young First Nations children living off-reserve in Canada." In Canadian Social Trends 90: 73-82. http://www.statcan.gc.ca/bsolc/ olc-cel/olc-cel?catno=11-008-X201000211336\&lang=eng

Bougie, E., Wright, S. C., \& Taylor, D. M. (2003). Early Heritage Language Education and the Abrupt Shift to a Dominant Language Classroom: Impact on the Personal and Collective Esteem of Inuit Children in Arctic Québec. International Journal of Bilingual Education and Bilingualism 6: 349-73.

Chandler, M. J. 2006. "Cultural Continuity in the Face of Radical Social Change: Language Preservation as a Protective Factor against Suicide in First Nations Youth." Paper presented at Raising Our Voices, Annual Language Conference, Cornwall, Ontario, August.

Chandler, M.J., and C.E.Lalonde. 2008. "Cultural Continuity as a Protective Factor against Suicide in First Nations Youth." In Hope or Heartbreak: Aboriginal Youth and Canada's Future, special 
issue, Horizons 10 (1): 68-72.

http://policyresearch.gc.ca/doclib/HOR_v10n1 200803 e.pdf.

Clatworthy, S.J. 2009. "Mobility and Migration Patterns of Aboriginal Populations in Canada, 2001-2006." Canadian Diversity / Diversité canadienne, 7 (3): 43-51.

Clatworthy, S.J. and M.J. Norris. Forthcoming. "Aboriginal Mobility and Migration in Canada: Trends, Recent Patterns and Implications, 1971 to 2006." In Aboriginal Populations-Social, Demographic, and Epidemiological Dimensions, ed. Frank Trovato and Anatole Romaniuc. Edmonton: University of Alberta Press.

Crystal, David 2000. Language Death. Cambridge: Cambridge University Press.

Guèvremont, A. and D. E. Kohen. 2011. "Knowledge of an Aboriginal language and school outcomes for children and adults." International Journal of Bilingual Education and Bilingualism. Forthcoming. http://dx.doi.org/10.1080/13670050.2011.581268

Kinkade, M.D. 1991. "The Decline of Native Languages in Canada. In Endangered Languages, ed. Robert H. Robins and Eugenius M. Uhlenbeck, 157-76. Oxford: Berg Publishers.

Louis, W. and D. M. Taylor. 2001. «When the survival of a language is at stake: The future of Inuttitut in arctic Québec.” Journal of Language and Social Psychology 20: 111-43. http://dx.doi.org/10.1177/0261927X01020001006

Moseley, Christopher, ed. 2010. Atlas of the World's Languages in Danger. 3rd ed. Paris: UNESCO Publishing. http://www.unesco.org/culture/ en/endangeredlanguages/atlas.

Norris, M.J. 1998. “Canada's Aboriginal Languages.” Canadian Social Trends 51 (Winter): 8-16. Ottawa: Statistics Canada, Catalogue. no. 11-008. 
- - - 2003. "From Generation to Generation: Survival and Maintenance of Canada's Aboriginal Languages within Families, Communities and Cities." In Maintaining the Links: Language, Identity and the Land, Proceedings of the Seventh Conference presented by the Foundation for Endangered Languages, Broome, Western Australia, 22nd-24th September, ed. J. Blythe and R. McKenna Brown, 58-65. Bath, UK: FEL.

- - - .2004. "Status, Use and Accessibility of Canada's Aboriginal languages within Communities and Cities." Poster presented at the Eighth Conference of the Foundation for Endangered Languages, Institute d'Estudis Catalans, Barcelona.

- - - .2006. “Aboriginal Languages in Canada: Trends and Perspectives on Maintenance and Revitalization." In Aboriginal Policy Research: Moving Forward, Making a Difference, vol.3., ed. J. P. White, S. Wingert, D. Beavon, and P. Maxim, 197-226. Toronto: Thompson Educational Publishing.

- - . 2007. "Aboriginal Languages in Canada: Emerging Trends and Perspectives on Second Language Acquisition." Canadian Social Trends 83: 19-27. http://www.statcan.calenglish/freepub/11-008XIE/2007001/pdf/11-008-XIE20070019628.pdf.

- - - 2008. "Voices of Aboriginal Youth Today: Keeping Aboriginal Languages Alive for Future Generations." In Hope or Heartbreak: Aboriginal Youth and Canada's Future, special issue, Horizons 10 (1): 60-7. http://policyresearch.gc.caldoclib/HOR v10n1 200803 e.pdf.

- - - 2008. "Voices of Aboriginal youth today: Keeping Aboriginal languages alive for future generations (Learning Sources for Children)." Presentation at Language, Culture and Mind 3, University of Southern Denmark, Odense, Denmark, 14-16 July. http://www. $1 \mathrm{~cm} . s d u . d k /$ index.php?id=1467.

- - . 2009. "The Role of First Nations Women in Language Continuity 
and Transition." In Restoring the Balance: First Nations Women, Community and Culture, ed. Gail Guthrie Valaskakis, Madeleine Dion Stout, and Eric Guimond, 313-53. Winnipeg: University of Manitoba Press.

- - - 2010. "Canada and Greenland." In UNESCO Atlas of the World's Languages in Danger. 3rd ed., ed. Christopher Moseley, 113-21. Paris: UNESCO Publishing.

- - - .2011. “Aboriginal Languages in Canada: Generational Perspectives on Language Maintenance, Loss and Revitalization," In Visions of the Heart: Canadian Aboriginal Issues, 3rd ed., ed. David Long and Olive P. Dickason, 113-48. Don Mills, ON: Oxford University Press.

- - - . Forthcoming. "Aboriginal Languages within Canada's Friendship Centre Areas: State, Diversity, Prospects and Implications, 2006 Census." In Complexities, Challenges, Opportunities: Urban Aboriginal Communities in Canada, ed. P. Dinsdale, C. Hanselmann and J.P. White. Toronto: Thompson Educational Publishing Inc.

Norris, M.J., and L. Jantzen. 2003. “Aboriginal Languages in Canada's Urban Areas: Characteristics, Considerations and Implications." In Not Strangers in These Parts: Urban Aboriginal Peoples, ed. David Newhouse and Evelyn Peters, 93-117. Ottawa: Policy Research Initiative.

Norris, M.J., and Karen MacCon. 2003. “Aboriginal Language Transmission and Maintenance in Families: Results of an Intergenerational and Gender-based Analysis for Canada, 1996." In Aboriginal Conditions: The Research Foundations of Public Policy, ed. Jerry White, Paul Maxim, and Dan Beavon, 165-96. Vancouver: UBC Press.

Norris, M.J., and M. Snider. 2008. "Endangered Aboriginal Languages in Canada: Trends, Patterns and Prospects in Language Learning." In Endangered Languages and Language Learning, ed. Tjeerd de Graaf, Nicholas Ostler, and Reinier Salverda. Proceedings of 
the XII Conference of the Foundation for Endangered Languages, Fryske Academy and Mercator European Research Centre, Leeuwarden, The Netherlands, 24-7 September. http://recherchepolitique.gc.ca/doclib/AboriginalBook e.pdf.

Norris, M.J. and S. Clatworthy. 2011. "Urbanization and Migration Patterns of Aboriginal Populations in Canada: A Half Century in Review (1951 to 2006)." Aboriginal Policy Studies 1 (1): 13-77. http:// ejournals.library.ualberta.ca/index.php/aps/1/1/NorrisClatworthy. $p d f$

Peters, Evelyn. J. 2011. "Emerging Themes in Academic Research in Urban Aboriginal Identities in Canada 1996-2010." Aboriginal Policy Studies 1 (1): 78-105. http://ejournals.library.ualberta.ca/index.php/aps/1/1/Peters.pdf.

Rust, Christa. 2010. "Measuring Progress, Strengthening Governance, and Promoting Positive Change: Developing Sustainability Indicators with Winnipeg's Urban First Nations Community." In Aboriginal Policy Research: Exploring the Urban Landscape, ed. Jerry P. White and Jodi Bruhn, 55-65. Toronto: Thompson Educational Publishing.

RCAP (Royal Commission on Aboriginal Peoples). 1996a. Report, vol. 3 , Gathering Strength, Ottawa: Minister of Supply and Services Canada.

RCAP (Royal Commission on Aboriginal Peoples). 1996b. Report, vol. 4, Perspectives and Realities. Ottawa: Minister of Supply and Services Canada.

Smith K., L. Findlay, and S. Crompton. 2010. "Participation in Sports and Cultural Activities among Aboriginal Children and Youth.” In Canadian Social Trends, Statistics Canada Catalogue no. 11-008X: 49-56. July 13. http://www.statcan.gc.ca/pub/11-008-x/2010002/ article/11286-eng.pdf . 
Statistics Canada. 2003. Aboriginal Peoples Survey 2001 Initial Findings: Well-being of the Non-reserve Aboriginal Population. Catalogue no. 89-589-XIE. Ottawa: Minister of Industry. http://www.statcan. gc.ca/pub/89-589-x/89-589-x2003001-eng.pdf.

- - - 2003a. Aboriginal Peoples of Canada: A Demographic Profile, 2001 Census. Analysis Series, 2001 Census. Catalogue no. 96F0030XIE2001007. Minister of Industry, 2003. http://www. statcan.gc.ca/bsolc/olc-cel/olc-cel?catno=96F0030XIE2001007\&la ng=eng.

- - . 2008: Aboriginal Peoples in Canada in 2006: Inuit, Métis and First Nations, 2006 Census. Catalogue no. 97-558-XIE. Ottawa: Minister of Industry. http://www12.statcan.ca/english/census06/ analysis/aboriginal/pdf/97-558-XIE2006001.pdf.

- - - . 2009. "Selected Findings from 2006: Aboriginal Children's Survey; First Nations People; Métis in Canada; Inuit in Canada." Special issue, Canadian Social Trends. Catalogue no. 11-008, http://abdc.bc.ca/uploads/file/10\%20Links/04\%20Data/11-008XPE\%20Special\%20edition\%202009\%20(2).pdf.

- - - . 2010. “2006 Census Dictionary,” Census Operations Division, Census Year 2006. Published by authority of the Minister responsible for Statistics Canada, (C) Minister of Industry, January 2010, Catalogue no. 92-566-X. http://www12.statcan.gc.ca/ censusrecensement/2006/ref/dict/pdf/92-566-eng.pdf.

Task Force on Aboriginal Languages and Cultures. 2005. Towards a new beginning: A foundation report for a strategy to revitalize First Nations, Inuit and Métis language and cultures. Ottawa, ON: Department of Canadian Heritage

Tulloch, Shelley. 2005. "Inuit Youth: The Future of Inuktitut." In Proceedings of the 14th Inuit Studies Conference, ed. R.O. van Everdingen (comp.), 285-300. The Arctic Institute of North America, University of Calgary, Calgary, Alberta, Canada. http://pubs.aina. ucalgary.calaina/14thISCProceedings.pdf. 
Tulloch, Shelley. 2008. "Uqausirtinnik Annirusunniq-Longing for Our Language." In Hope or Heartbreak: Aboriginal Youth and Canada's Future, special issue, Horizons 10 (1): 73-76. http://policyresearch. gc.ca/doclib/HOR v10n1 200803 e.pdf.

UNESCO. 2009. “UNESCO's Interactive Atlas of the World's Languages in Danger: Statistics by Country or Area.' February 172009. http://www.unesco.org/culture/ich/UNESCOEndangeredLanguages-Statistics-20090217.xls. (see now: http:// www.unesco.org/culture/en/endangeredlanguages/atlas)

Wright, S. C., and D. M. Taylor. 1995. "Identity and the language in the classroom: Investigating the impact of heritage versus second language instruction on personal and collective self esteem." Journal of Educational Psychology 87: 241-52.

http://dx.doi.org/10.1037//0022-0663.87.2.241 